\title{
Study on the Instability Characteristics and Bolt Support in Deep Mining Roadways Based on the Surrounding Rock Stability Index: Example of Pansan Coal Mine
}

\author{
Jucai Chang, ${ }^{1}$ Kai He $\mathbb{D}^{1},{ }^{1}$ Zhiqiang Yin, ${ }^{1}$ Wanfeng $\mathrm{Li}^{2}{ }^{2}$ Shihui Li, ${ }^{2}$ and Dongdong Pang ${ }^{1}$ \\ ${ }^{1}$ Key Laboratory of Safe and Effective Coal Mining of the Ministry of Education, Anhui University of Science and Technology, \\ Huainan 232001, China \\ ${ }^{2}$ Huainan Mining Industry (Group) Corporation Ltd., Huainan 232001, China
}

Correspondence should be addressed to Kai He; e_2718281828459045@foxmail.com

Received 8 June 2020; Revised 6 August 2020; Accepted 21 August 2020; Published 10 September 2020

Academic Editor: Fengqiang Gong

Copyright (C) 2020 Jucai Chang et al. This is an open access article distributed under the Creative Commons Attribution License, which permits unrestricted use, distribution, and reproduction in any medium, provided the original work is properly cited.

In view of the influence of mining stress on the stability of the surrounding rock of inclined roof mining roadways in deep mines, the surrounding rock stability index is defined and solved based on the rock strength criterion and the stress distribution. The mining roadway of the $17102(3)$ working face of the Pansan Coal Mine is used as the engineering background and example. The surrounding rock' stabilities under the conditions of no support and bolt support are analyzed according to the surrounding rock's stability index and the deformation data. The results show that the areas of low wall and high wall instability are $1.68 \mathrm{~m}^{2}$ and $2.12 \mathrm{~m}^{2}$, respectively, and the low wall is more stable than the high wall; the areas of the roof and floor instability are $0.33 \mathrm{~m}^{2}$ and $0.35 \mathrm{~m}^{2}$, respectively, and the roof and floor are more stable than the two sides. During mining, the area of instability greatly increases at first, then decreases to 0 , and reaches a maximum value at the peak of the abutment pressure. The stability of the surrounding rock decreases first and then increases. Compared with the end anchoring bolt support, the full-length anchoring bolt support reduces the area of instability to a greater extent, and the full-length anchoring bolt support effect is better. The surrounding rock in the end anchoring zone and the full-length anchoring zone began to deform significantly at $200 \mathrm{~m}$ and $150 \mathrm{~m}$ from the working face, respectively. This indicates that the control effect of the full-length anchoring bolt support is better and verifies the rationality of the surrounding rock stability index to describe the instability characteristics. This research method can provide a theoretical reference for analysis of the stability characteristics and support design of different cross-section roadways.

\section{Introduction}

With the increasing depletion of shallow coal resources, deep mining in various mining areas has become the norm in China. In high ground stress environments, a deep mining roadway often shows the characteristics of soft rock. It is difficult to control the deformation of the mining roadway when it is affected by mining stress. Effective control of the surrounding rock deformation of the mining roadway is the premise to ensure smooth mining of the working face. In deep coal resources, the inclined coal seam is widely distributed and occupies a large proportion of the area. When mining an inclined coal seam, to facilitate the management of the roof of the mining roadway, the mining roadway is often driven along the roof of the coal seam, forming an inclined roof mining roadway (IRMR). With the characteristics of supporting fast driving speeds and simple construction technology, IRMR is widely used in inclined coal seams. The stability characteristics of the surrounding rock of IRMR have their own features, which has attracted the attention of the field engineers and rock mechanics workers.

As the core content of roadway support theory, the stability of a roadway's surrounding rock is always one of the key research directions in mining engineering. Many scholars at home and abroad, using field engineering practices, experimental results, and theoretical reasoning analyses, have carried out in-depth research on the stability of the surrounding rock and bolt support mechanism from 
different angles and have established many classic theories, such as the combined arch theory [1], the plasticity zone theory [2, 3], and the broken rock zone theory [4]. In IRMR, because of the existence of corners, when affected by mining stress, there is a large concentration of stress in these corners, resulting in a large difference between the surrounding rock stability characteristics of IRMR and that of regular crosssection roadways such as circular, elliptical, and straight wall arches.

This study on the stability characteristics of surrounding rock and the bolt supporting mechanism of IRMR affected by mining stress is of great significance to the surrounding rock control of IRMR in deep mining. Based on this, this paper proposes a surrounding rock stability index (SRSI), which can quantitatively describe the stability of the surrounding rock based on the stress distribution of IRMR and the rock strength criterion. SRSI provides the theoretical basis for the study of the evolution law of the surrounding rock stability characteristics and the bolt support mechanism of different anchorage forms of IRMR under the influence of mining stress.

In terms of research on the surrounding rock stability of roadways with irregular cross sections, such as inclined roof cross sections, the numerical simulation method is mainly used to carry out relevant research. Some of the research results are as follows: G. Li and others used FLAC3D numerical simulation software to study the distribution of the surrounding rock plastic zone, the principal stress difference, and the deformation characteristics of six tunnel section shapes, namely, rectangular, straight walls with arched tops, horseshoe shaped, three centered arches, circles, and ellipse, and proposed the concept of equivalent excavation and void reinforced areas [5]. Q. Meng and others used FLAC3D numerical simulation software to study the surrounding rock deformation characteristics and the surrounding rock distribution of the plastic zone of six kinds of cross-section shape roadways, namely, rectangular, trapezoid, straight wall arches, horseshoes, ovals, and round shapes. The results show that the round and oval shapes are the optimal cross-section shapes for deep roadway under high ground stress [6]. L. Hu and others used ANSYS software to simulate and analyze the influence of roadway section structure on the surrounding rock deformation. The results show that the section form has an appreciable impact on both the horizontal displacement and the vertical displacement of the surrounding rock under the same conditions, and the rectangular section has the greatest impact [7]. Although numerical simulation can be used to study and solve a wide range of engineering technical problems, numerical simulation can only obtain quantitative conclusions, and some problems cannot be judged qualitatively. At the same time, the research method of numerical simulation is still based on a theoretical basis, and the imperfection of theoretical research limits the application and development of numerical simulations.

In view of the research on the bolt support mechanism with different anchorage forms, scholars at home and abroad have conducted thorough studies and achieved many results. For the end anchored bolt support, there are mainly classical theories such as the combined arch theory [1], the broken rock zone theory [3], the suspension theory [8,9], and the dynamic response theory [10], which play an irreplaceable role in the design of bolt support. For the full-length anchoring bolt support, there have been numerous studies, and some important achievements are listed as follows: J. Chen and others used an analytical model to study the load transfer behavior of fully grouted rock bolts. The results show that the axial load in the rock bolt decayed from the loaded end to the free end independent of the pull-out load. However, the trend of the load distribution curve was influenced by the pull-out load [11]. M. H. Aghchai and others presented an analytical method to use this curve for determining the bond (bolt-grout and grout-rock interface) shear strength parameters [12]. Cui and others aimed to propose new numerical procedures for elastoplastic analysis of the interactions between fully grouted bolt and rock with slip and nonslip cases at a potential-failure interface [13]. Zou and Zhang investigated the dynamic evolution characteristic of the bond strength at the interface of a bolt and a rock mass under an axial tensile load and the mechanical behavior of fully grouted bolts in situ considering the nonuniform stress of the surrounding rock along the bolts [14]. C. Wu and others studied the tensile behavior of unreinforced and reinforced rock with fully grouted bolts and an empirical approach was proposed to predict the strength of rock reinforced with fully grouted bolts [15]. Liu and others established an analytical model for the interaction between the bolt and surrounding rock based on the bearing mechanism of fully grouted rock bolts, deduced the corresponding controlled differential equation for load transfer, and obtained the stress distributions of the anchorage body [16]. Chen and others employed the elastic theory of a semi-infinite length beam and approximate differential equation of the deflection curve (elastic and elastoplastic) to analyze the lateral behavior of a bolt under surrounding rock pressures [17]. Although there is much research on the mechanisms of bolt support with different anchorage forms in the existing literature, most of them are based on the condition that the mechanical state of the surrounding rock remains unchanged. However, owing to the influence of mining stress, the mechanical state of the surrounding rock is obviously changed, so it is necessary to consider the influence of the change of the surrounding rock's mechanical state when studying bolting mechanisms.

To summarize, this paper proposes a method for the surrounding rock stability analysis with reference to previous research results. Based on the strength criterion and the stress distribution of the surrounding rock, SRSI is defined to measure the surrounding rock stability characteristics. Using the MohrCoulomb strength criterion and the complex function method proposed by Muskhelishvili [18-23], the analytical solution of SRSI is obtained. Based on the study of the 17102(3) working face of the Pansan Coal Mine (PCM) in the Huainan, China, the area of the unstable area (AUA) of the surrounding rock is calculated according to SRSI, and then the evolution law of surrounding rock stability characteristics is analyzed when IRMR is affected by mining stress in deep mining. By changing the boundary conditions, the distribution of the SRSI with 
supporting conditions and the change law of AUA with the mining of the working face are obtained. Combined with the observation data of the IRMR deformation, the supporting effect and mechanism of the end anchoring bolt support and the full-length anchoring bolt support are analyzed. Finally, this paper summarizes the research results and gives relevant conclusions.

\section{Analysis Method of Surrounding Rock Stability Characteristics}

2.1. Definition and Solution of SRSI. The strength criterion of rock can be expressed by an equation describing the function relationship between the principal stresses:

$$
\widehat{\sigma}_{1}=f\left(\sigma_{2}, \sigma_{3}\right)
$$

In equation (1), $\widehat{\sigma}_{1}$ represents the maximum principal stress of the critical failure state; $\sigma_{2}$ represents the intermediate principal stress; $\sigma_{3}$ represents the minimum principal stress; function $f$ represents the strength criterion. When the real maximum principal stress $\sigma_{1}$ is less than the critical failure maximum principal stress $\widehat{\sigma}_{1}$, the surrounding rock is in a stable state. The smaller $\sigma_{1}$ is, the more stable the surrounding rock is. On the contrary, when the surrounding rock is in a state of instability, the larger $\sigma_{1}$ is, the worse the stability of the surrounding rock is. According to this, SRSI can be defined as

$$
K=\frac{\widehat{\sigma}_{1}}{\sigma_{1}} .
$$

In equation (2), $K$ represents SRSI. SRSI reflects the relationship between the actual maximum principal stress $\sigma_{1}$ and the critical failure maximum principal stress $\widehat{\sigma}_{1}$. When $K$ is equal to 1 , the surrounding rock is in a critical state of failure; when $K$ is greater than 1 , the surrounding rock is in a stable state; when $K$ is less than 1, the surrounding rock is in a state of failure, that is, an unstable state, so this area is called an unstable area (UA). According to this, AUA can be defined to evaluate the stability of the surrounding rock and the bolt support effect. The smaller AUA is, the more stable the surrounding rock is. The definition of AUA is as follows:

$$
S=\iint_{\Omega} H(1-K(x, y)) \mathrm{d} s .
$$

In equation (3), $\Omega$ represents the specific area in the surrounding rock, which can be the entire surrounding rock, the roof and floor, the two sides, or other designated areas; $\mathrm{H}$ represents the Heaviside step function, and the Heaviside function $\mathrm{H}$ is as follows:

$$
H(t)= \begin{cases}1, & t>0 \\ 0.5, & t=0 \\ 0, & t<0 .\end{cases}
$$

In this paper, the basic form of the Mohr-Coulomb rock strength criterion is used to calculate $K$. When the MohrCoulomb strength criterion is expressed by principal stress, it is as follows:

$$
\widehat{\sigma}_{1}=\frac{1+\sin \phi}{1-\sin \phi} \sigma_{3}+\frac{2 c \cdot \cos \phi}{1-\sin \phi} .
$$

In equation (5), $\phi$ represents the internal friction angle and $c$ represents cohesion. By substituting equation (5) into equation (2), the expression of $K$ under the Mohr-Coulomb criterion can be obtained as follows:

$$
K=\frac{(1+\sin \phi) \sigma_{3}+2 c \cdot \cos \phi}{(1-\sin \phi) \sigma_{1}}
$$

The complex function method proposed by Мусчелишвили is used to solve the principal stress distribution of the surrounding rock of IRMR [18-23]. The specific ideas are as follows: first, the outer area of IRMR is mapped to the unit circle on the complex plane with a conformal mapping function; second, the complex function of the representative stress distribution is solved by using relevant knowledge of the complex analysis according to the boundary conditions; finally, the principal stress distribution is calculated with the complex function.

The deep buried IRMR can be regarded as an infinite plane orifice. The vertical pressure $\sigma_{V}$, horizontal pressure $\sigma_{H}$, and shear stress $\tau$ are used to represent the total pressure on the surrounding rock. The stress diagram of IRMR is shown in Figure 1.

According to the Riemann mapping theorem [18, 24], the surrounding rock area of IRMR can be mapped into a unit circle via the conformal mapping function $\omega(\xi)$. In general, it is very difficult to find the exact conformal mapping function to use. An effective method is to expand it into a Laurent series and take the finite term as the approximation of the conformal mapping function $\omega(\xi)$. In this case, the conformal function $\omega(\xi)$ can be expressed as

$$
z=\omega(\xi)=\sum_{n=-1}^{n=N} C_{n} \xi^{n} .
$$

In equation (7), $z=x+i y$ represents the coordinate of the point on the $z$ plane where the roadway section is located; $\xi=$ $\rho e^{i \theta}$ represents the coordinate of the point on the $\xi$ plane where the unit circle is located; $C_{n}=A_{n}+i B_{n}$ represents the complex coefficient, whose value is related to the shape of the roadway section; $N$ represents the order of the Laurent series. Then the search for an exact conformal mapping function is transformed into a search for a group of the complex coefficients $C_{n}$ for approximation. According to the algorithm proposed in [24-29], this paper uses scientific calculation software to program and solve the complex coefficient $C_{n}$. The corresponding relationship between the coordinates of the points on the $z$ plane and the $\xi$ plane is as follows:

$$
\left\{\begin{array}{l}
x=\operatorname{Re}\left(\omega\left(\rho e^{i \theta}\right)\right), \\
y=\operatorname{Im}\left(\omega\left(\rho e^{i \theta}\right)\right) .
\end{array}\right.
$$

In equation (8), the function Re represents the real part of the complex number; the function Im represents the imaginary part of the complex number. 


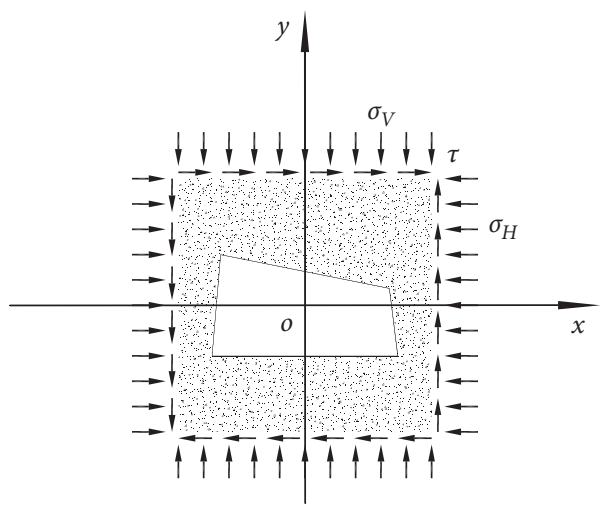

Figure 1: Stress diagram of IRMR.

The stress of the surrounding rock can be determined with two complex functions, $\varphi(z)$ and $\psi(z)$, in the complex plane. To solve the distribution of the principal stress in the surrounding rock of IRMR, the form of the complex function is as follows:

$$
\left\{\begin{array}{l}
\varphi(z)=\frac{\sigma_{V}+\sigma_{H}}{4} \cdot \omega(\xi)+\varphi_{0}(\xi), \\
\psi(z)=\sqrt{\left(\sigma_{V}-\sigma_{H}\right)^{2}+4 \tau^{2}} \cdot \frac{e^{2 i \alpha} \omega(\xi)}{4}+\psi_{0}(\xi) .
\end{array}\right.
$$

In equation (9), the complex functions $\varphi_{0}(\xi)$ and $\psi_{0}(\xi)$ represent the analytic function satisfying the Cauchy-Riemann condition in the definition domain, which can be expanded to Taylor series, as shown in equation (10). And the $\alpha$ value is as shown in equation (11). One has

$$
\left\{\begin{array}{l}
\varphi_{0}(\xi)=\sum_{n=0}^{n=+\infty} a_{n} \xi^{n}, \\
\psi_{0}(\xi)=\sum_{n=0}^{n=+\infty} b_{n} \xi^{n} . \\
\alpha=\arctan \left(\frac{\sigma_{V}-\sigma_{H}+\sqrt{\left(\sigma_{V}-\sigma_{H}\right)^{2}+4 \tau^{2}}}{2 \tau}\right) .
\end{array}\right.
$$

In equation (10), $a_{n}$ and $b_{n}$ represent the complex coefficients. The complex functions $\varphi_{0}(\xi)$ and $\psi_{0}(\xi)$ can be obtained using the boundary conditions of the roadway surface. According to Harnack's theorem [18], the boundary conditions of the roadway surface can be equivalent to two functional equations as

$$
\left\{\varphi_{0}(\zeta)+\frac{1}{2 \pi i} \int \frac{\omega(\zeta)}{\Gamma} \cdot \frac{\overline{\varphi_{0}^{\prime}(\zeta)}}{\overline{\omega^{\prime}(\zeta)}} d \zeta=\frac{1}{2 \pi i} \int_{\Gamma} \frac{f_{0}}{\zeta-\xi} \mathrm{d} \zeta, \psi_{0}(\zeta)+\frac{1}{2 \pi i} \int \frac{\overline{\omega(\zeta)}}{\Gamma \omega^{\prime}(\zeta)} \cdot \frac{\varphi_{0}^{\prime}(\zeta)}{\zeta-\xi} d \zeta+\bar{a}_{0}=\frac{1}{2 \pi i} \int_{\Gamma} \frac{\bar{f}_{0}}{\zeta-\xi} \mathrm{d} \zeta\right.
$$

In equation (12), $\Gamma$ represents the boundary of the roadway section; $\zeta$ represents the point on the boundary $\Gamma$; $\overline{\omega(\xi)}$ is the complex conjugate of $\omega(\xi) ; \overline{\varphi_{0}^{\prime}(\zeta)}$ is the complex conjugate of $\varphi_{0}^{\prime}(\zeta) ; f_{0}$ and $\bar{f}_{0}$ represent the reduced boundary condition as follows:

$$
\left\{\begin{array}{l}
f_{0}=-\frac{1}{2}\left[\left(\sigma_{V}+\sigma_{H}\right) \cdot \omega(\zeta)-\sqrt{\left(\sigma_{V}-\sigma_{H}\right)^{2}+4 \tau^{2}} \cdot e^{2 i \alpha} \cdot \overline{\omega(\zeta)}\right] \\
\overline{f_{0}}=-\frac{1}{2}\left[\left(\sigma_{V}+\sigma_{H}\right) \cdot \overline{\omega(\zeta)}-\sqrt{\left(\sigma_{V}-\sigma_{H}\right)^{2}+4 \tau^{2}} \cdot e^{-2 i \alpha} \cdot \omega(\zeta)\right] .
\end{array}\right.
$$

By substituting equation (10) into equation (12), the integral is solved by using the Cauchy integral formula. Then, the complex coefficients $a_{n}$ and $b_{n}$ can be obtained by comparing the coefficients on both sides of equation (12), and the complex functions $\varphi_{0}(\xi)$ and $\psi_{0}(\xi)$ can be obtained.
Then, the stress distribution of surrounding rock can be obtained with the following equation:

$$
\left\{\begin{array}{l}
\sigma_{\rho}+\sigma_{\theta}=4 \operatorname{Re}\left(\frac{\varphi^{\prime}(\xi)}{\omega \prime(\xi)}\right) \\
\sigma_{\rho}-\sigma_{\theta}+2 i \tau_{\rho \theta}=\frac{2 \xi^{2}}{\rho^{2}} \cdot\left[\frac{\overline{\omega(\xi)}}{\overline{\omega \prime(\xi)}} \cdot\left(\frac{\varphi^{\prime}(\xi)}{\omega \prime(\xi)}\right)^{\prime}+\frac{\psi^{\prime}(\xi)}{\overline{\omega \prime(\xi)}}\right] .
\end{array}\right.
$$

In equation (14), $\sigma_{\rho}$ represents the normal stress in the direction of the coordinate line $\rho ; \sigma_{\theta}$ represents the normal stress in the direction of the coordinate line $\theta ; \tau_{\rho \theta}$ represents the shear stress in the direction of the coordinate lines $\rho$ and $\theta$.

Because the stress calculated by equation (14) is in an orthogonal curvilinear coordinate system determined by the 
conformal mapping function $\omega(\xi)$, the principal stress component can be directly calculated as

$$
\left\{\begin{array}{c}
\sigma_{1}=\frac{\sigma_{\rho}+\sigma_{\theta}}{2}+\sqrt{\left(\frac{\sigma_{\rho}-\sigma_{\theta}}{2}\right)^{2}+\tau_{\rho \theta}^{2}}, \\
\sigma_{3}=\frac{\sigma_{\rho}+\sigma_{\theta}}{2}-\sqrt{\left(\frac{\sigma_{\rho}-\sigma_{\theta}}{2}\right)^{2}+\tau_{\rho \theta}^{2}} .
\end{array}\right.
$$

By substituting the main principle into equation (6), the analytical solution of SRSI can be obtained.

2.2. Effect of Mining Stress. Mining stress mainly affects the surrounding rock stress conditions and the strength parameters of the surrounding rock. According to the research results on the abutment pressure in [30-34], the exponential model is used to describe the abutment pressure, which is used to estimate the vertical pressure $\sigma_{V}(l)$ of the surrounding rock:

$$
\begin{aligned}
\sigma_{V}(l)= & H\left(l_{s}-l\right) \cdot \frac{k_{s} \sigma_{V}^{0}}{e^{a l_{s}}-1} \cdot\left(e^{a l}-1\right) \\
& +H\left(l-l_{s}\right) \cdot \sigma_{V}^{0} \cdot\left[\left(k_{s}-1\right) e^{b\left(l_{s}-l\right)}+1\right] .
\end{aligned}
$$

In equation (16), $l$ represents the distance from the working face; $\sigma_{V}^{0}$ represents the vertical pressure of the original rock; $k_{s}$ represents the vertical stress concentration coefficient at the peak of the abutment pressure; $l_{s}$ represents the peak position of the abutment pressure; coefficients $a$ and $b$ are used to describe the change severity of the abutment pressure curve. The lateral pressure coefficient $\lambda$ and shear stress coefficient $\eta$ are defined as

$$
\begin{gathered}
\lambda=\frac{\sigma_{H}}{\sigma_{V}}, \\
\eta=\frac{\tau}{\sigma_{V}} .
\end{gathered}
$$

Assuming that the lateral pressure coefficient $\lambda$ and shear stress coefficient $\eta$ are constant in the mining process, the horizontal pressure $\sigma_{H}(l)$ and shear stress $\tau(l)$ of the surrounding rock of the roadway are

$$
\left\{\begin{array}{l}
\sigma_{H}(l)=\lambda \cdot \sigma_{V}(l), \\
\tau(l)=\eta \cdot \sigma_{V}(l) .
\end{array}\right.
$$

It is assumed that the cohesion of the surrounding rock is constant before the peak of the abutment pressure, decreases linearly after the peak of the abutment pressure, and is 0 at the working face. The internal friction angle of the surrounding rock changes little in the mining process, which is assumed to be constant. The cohesion $c(l)$ and the internal friction angle $\phi(l)$ are as follows:

$$
\left\{\begin{array}{l}
c(l)=H\left(l_{s}-l\right) \cdot \frac{c_{0} l}{l_{s}}+H\left(l-l_{s}\right) \cdot c_{0} \\
\phi(l)=\phi_{0} .
\end{array}\right.
$$

In equation (19), $c_{0}$ represents the cohesion of the protolith, and $\phi_{0}$ represents the internal friction angle of the protolith.

By substituting equations (16) and (18) into equation (9), the distribution of the principal stress of the surrounding rock of IRMR under the influence of mining can be obtained. By substituting the principal stress distribution and equation (19) into equation (6), the analytical solution of $K$ under the influence of mining can be obtained.

\section{Results and Discussion}

The 17102(3) face in the PCM of the Huainan Mining Group is a typical deep mining face with a mining depth of $700 \mathrm{~m}$. In the 17102(3) working face, one side of the mining roadway is the other side of the working face, which is solid coal. Its stress can reflect the influencing characteristics of the mining stress. The total length of the roadway is $1808 \mathrm{~m}$. The sections $0-180 \mathrm{~m}$ and $1380-1808 \mathrm{~m}$ away from the openoff cut adopt the end anchoring bolt support mode, while the section 180-1380 $\mathrm{m}$ adopts the full-length anchoring bolt support mode.

To facilitate the analysis of the stability of the surrounding rock of the roadway, the areas of the roof and floor and the two sides are divided. In the middle of the roof, the floor, and the two sides, a radial survey line is arranged in the vertical rock wall. A radial survey line is arranged in the diagonal direction at the corners of the roadway. A circular survey line is arranged on the roadway surface and $0.3 \mathrm{~m}$ into the surrounding rock. And the corners of roadway are numbered. The roadway section shape, the survey line position, the number of corners, the two-side area, and the roof and floor area are shown in Figure 2. In Figure 2, the orthogonal curvilinear coordinate system determined by the conformal mapping function $\omega(\xi)$ is also drawn. It is illustrated as a spider network coordinate system composed of circular coordinate line $\rho$ and radial coordinate line $\theta$ in the figure.

3.1. Distribution Law of Mining Stress in Roadway. The roof and floor of the 17102(3) working face are mudstone and sandy mudstone, which are similar to the mechanical properties of the coal seam and thus are combined. According to the in situ stress test results, $\sigma_{V}^{0}$ is $16.8 \mathrm{MPa} ; \sigma_{H}^{0}$ is $13.3 \mathrm{MPa}$; $\tau^{0}$ is $0.5 \mathrm{MPa} ; \lambda$ is $0.79 ; \eta$ is 0.03 . According to [30-34], as well as field mine pressure observation results, mining height, mining speed, hydraulic support parameters, and other relevant data, let $k_{s}=1.9, a=0.1$, and $b=0.03$. When the distance between the roadway and the working face is more than $250 \mathrm{~m}$, the roadway is not affected by mining stress. Substitute the above parameters into equation 


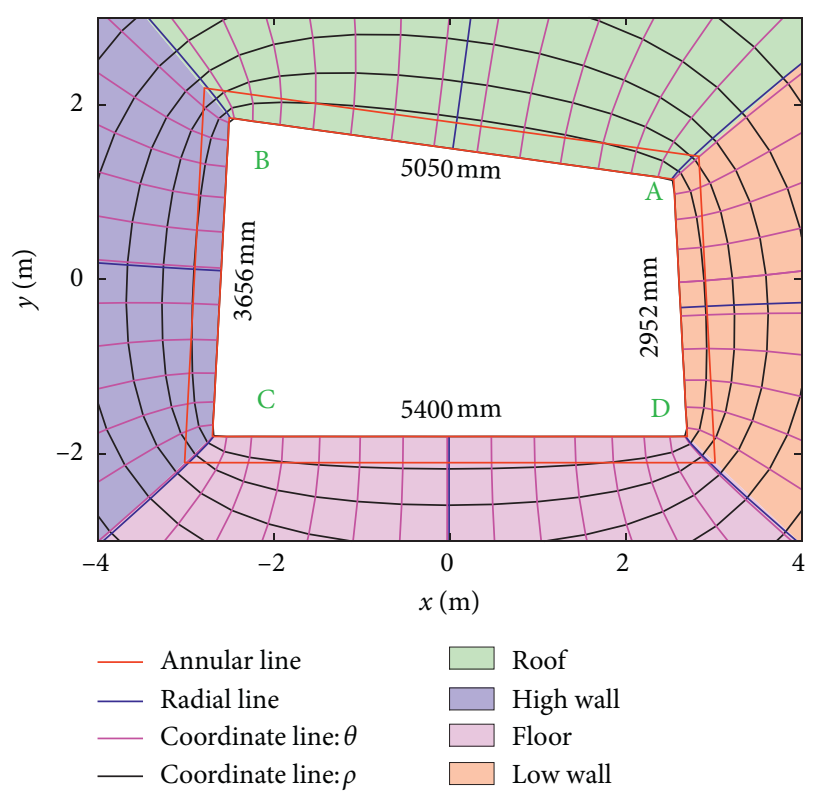

Figure 2: Schematic diagram of roadway section.

(16) to obtain the abutment pressure curve, as shown in Figure 3. It can be seen from Figure 3 that $\sigma_{V}$ increases first and then decreases with mining, reaching a maximum value $k_{s} \sigma_{\mathrm{V}}^{0}$ at $l=l_{s}$.

After the laboratory test and using different weights to determine the reduction coefficient, we obtain the rock mechanics parameters, which are more consistent with the actual site. When not affected by mining stress, let the cohesion $c_{0}$ be $6.2 \mathrm{MPa}$ and let the internal friction angle $\phi_{0}$ be $28^{\circ}$. According to equation (19), the change in the surrounding rock cohesion of the roadway with the mining can be obtained as shown in Figure 4. It can be seen from Figure 4 that $c$ is a constant before the peak of the abutment pressure, and after the peak, $c$ decreases linearly, reaching a minimum value of $c=0$ at the working face.

3.2. Distribution Law of SRSI in IRMR without Support. Without considering roadway support, SRSI in the vertical section of the 17102(3) working face is obtained at different positions $(l)$ in front of the advancing direction, and SRSIs of radial survey line and the circumferential line are obtained. They are as shown in Figures 5-7, respectively.

It is generally believed that when $l>250 \mathrm{~m}$, it is not affected by mining. It can be seen from Figure 5 that the distribution law of SRSI is similar when the roadway is affected by mining stress and when it is not affected by mining stress. In the roof and floor and the two sides of the roadway, there are unstable areas of the surrounding rock. It can be seen from Figure 6(a) that the minimum value of SRSI at the roof and floor radial survey lines is greater than 0 , as shown by arrows $b$ and $d$ in Figure 6(a), indicating that the UAs of the roof and floor are not connected, and the minimum value of SRSI at the two-side survey lines is less than 0 , as shown by arrows $a$ and $c$ in Figure 6(a), indicating that the UAs of the two sides are connected. From Figure 5, it can be clearly observed that there are two blue areas in the roof and floor, which are located at the two corners, respectively. With the mining of the working face, there is a trend of connectivity, indicating that the UAs of the roof and floor are located at the two corners, respectively, and with the mining of the working face, there is also a trend of connectivity. There is a blue area in each of the two sides, which is the arched distribution, and the arch corners are located at the roadway corners, indicating that the UAs of the two sides are an arched distribution and the arch corners are located at the roadway corners. The minimum value of SRSI is 0 , and the minimum value is located at the roadway corners, indicating that the stability of the roadway corners is worst in the surrounding rock of the roadway.

It can be seen from Figure 6(b) that, on the diagonals of the roadway, SRSI tends to be constant when it approaches the corners from the depth of the surrounding rock, as shown by arrows $e, f, g$, and $h$ in Figure 6(b). It can be seen from Figure 7 (a) that, on the roadway surface, SRSI tends to be 0 when approaching from the middle of the rock wall to the corners, as shown by arrows $i, j, k$, and $l$ in Figure $7(\mathrm{a})$. It can be seen from Figure 7(b) that SRSI near the corners increases suddenly, as shown by arrows $m, n, o$, and $p$ in Figure 7(b). Based on this, it can be found that the distribution of SRSI at the corners of IRMR has variability. So first, UA appears at the corners of IRMR and then develops to the middle of rock wall.

According to equation (3), when the distance from the working face is different, the AUAs of the roof and floor and the two sides are calculated, as shown in Figure 8. It can be seen from Figure 8 that the AUAs of the roof and floor and the two sides first increase and then decrease with mining of the working face. The maximum values of the AUAs of the roof and floor and the two sides appear at the peak of the abutment pressure, as shown by arrow $q$ in Figure 8 , indicating that the stability of the surrounding rock is the worst at the peak of the abutment pressure. Before the peak of the abutment pressure, with the mining, the AUAs of the roof and floor and the two sides first increase slowly, as shown in part (a) in Figure 8, and then increase rapidly, as shown in part (b) in Figure 8, which shows that the stability of the surrounding rock decreases slowly and then rapidly decreases before the peak of the abutment pressure. The AUA changes of the roof and floor are greater than that of the two sides, and the AUA change of the high wall area is greater than that of the low wall, indicating that the roof and floor are more affected by mining stress than the two sides, and the high wall is more affected by mining stress than the low wall. After the peak of the abutment pressure, the AUAs of the roof and floor and the two sides decrease rapidly and are reduced to 0 , as shown in part (c) in Figure 8, indicating that the stability of the surrounding rock of the roadway increased.

It can be seen from Figure 8 that the AUA curve of the low wall is below the AUA curve of the high wall. When the roadway is not affected by mining stress, the AUAs of the low wall and the high wall are $1.68 \mathrm{~m}^{2}$ and $2.12 \mathrm{~m}^{2}$, respectively. At the peak of the abutment pressure, the AUAs of the low wall and the high wall are increased to $2.81 \mathrm{~m}^{2}$ and $4.24 \mathrm{~m}^{2}$. This shows that the AUA of the low wall is smaller 


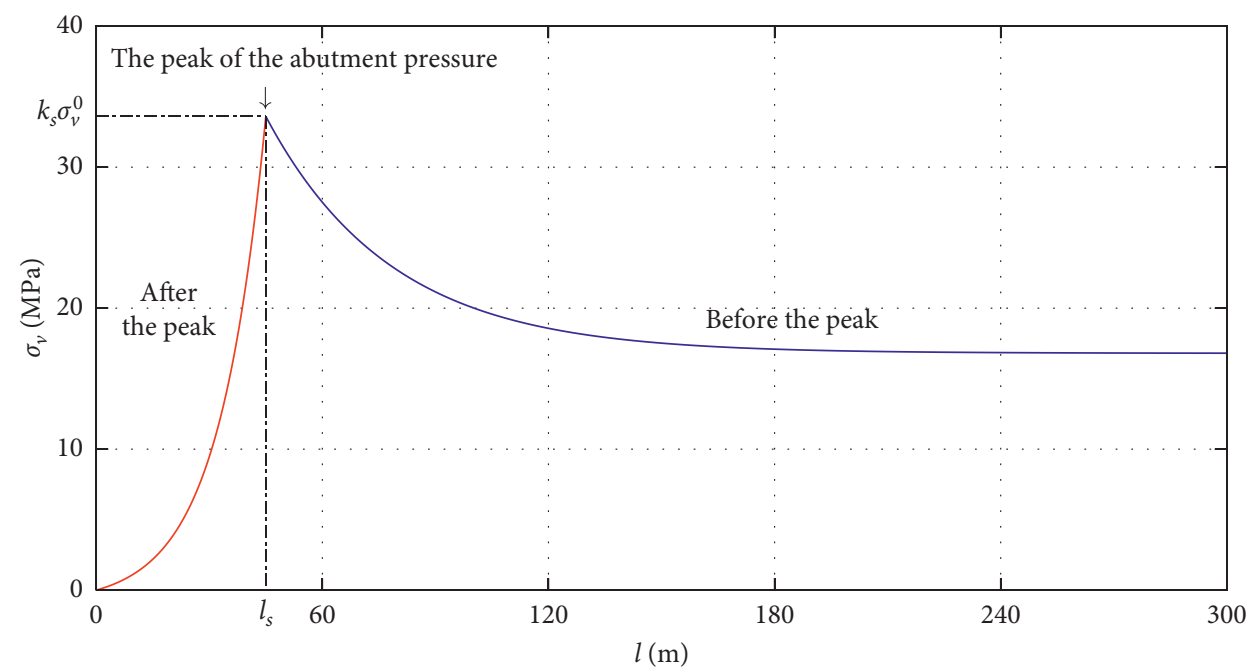

FIgURE 3: The abutment pressure curve.

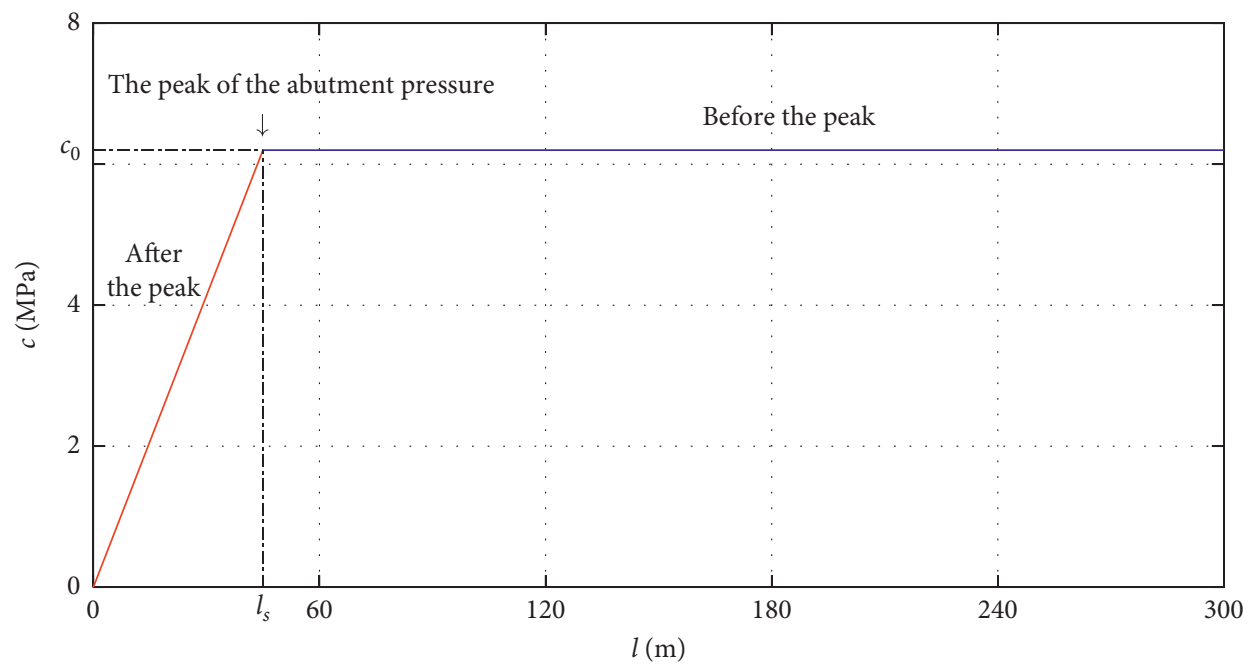

FIGURE 4: The cohesion of surrounding rock.

than that of the high wall; thus, the low wall is more stable. There is little difference between the AUA curves of the instability areas of the roof and floor. When the roadway is not affected by mining stress, the AUAs of the roof and floor are $0.33 \mathrm{~m}^{2}$ and $0.35 \mathrm{~m}^{2}$, respectively. At the peak of the abutment pressure, the AUAs of the roof and floor increase to $4.11 \mathrm{~m}^{2}$ and $3.97 \mathrm{~m}^{2}$. The results show that the AUA difference between the roof and floor is small, and the stabilities of the roof and floor are equal. Before the peak of the abutment pressure and being less affected by the mining stress, the AUA curve of the roof and floor is located below the AUA curve of the two sides, and the AUA of the roof and floor is less than that of the two sides, indicating that the roof and floor are more stable than the two sides.

3.3. Distribution Law of SRSI in IRMR with Different Anchoring Forms of Bolt Support. The main bolt supporting parameters of the roadway are as follows: 5 bolts are installed in the high wall, with a spacing of $800 \mathrm{~mm} ; 4$ bolts are installed in the low wall, with a spacing of $800 \mathrm{~mm}$; 7 bolts are installed in the roof, with a spacing of $750 \mathrm{~mm}$; all bolts are $2400 \mathrm{~mm}$ long, $22 \mathrm{~mm}$ diameter high-strength bolts, with an anchorage length of $400 \mathrm{~mm}$ in the end anchorage zone and $2200 \mathrm{~mm}$ in the full-length anchorage zone, with a preload of $15 \mathrm{kN}$. 4 cables are installed in the roof, with a spacing of $1200 \mathrm{~mm}$. Cables are $6300 \mathrm{~mm}$ long, $22 \mathrm{~mm}$ diameter anchor cables, with an anchorage length of $1200 \mathrm{~mm}$ and a preload of $180 \mathrm{kN}$. At the same time, other supporting materials such as anchor net and steel belt shall be used. The roadway section parameters and support scheme are shown in Figure 9.

In this paper, only the influence of bolt resistance on the stability of the surrounding rock is considered. According to the calculation method of the working resistance of bolts with different anchorage lengths in $[11,13]$, the variations of working resistance of end anchorage and full-length anchorage bolts during the mining are obtained. By changing 


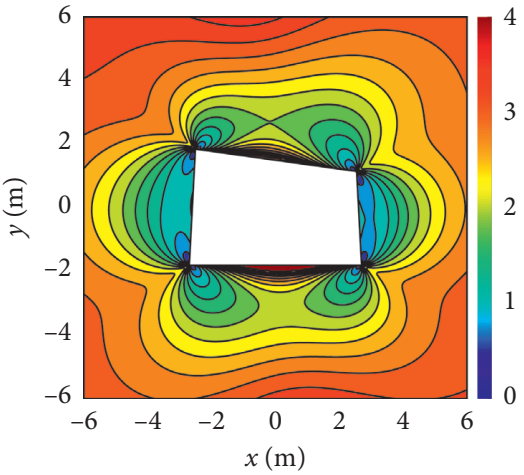

(a)

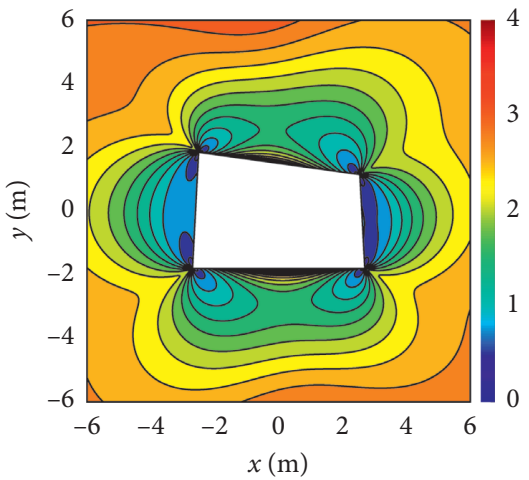

(d)

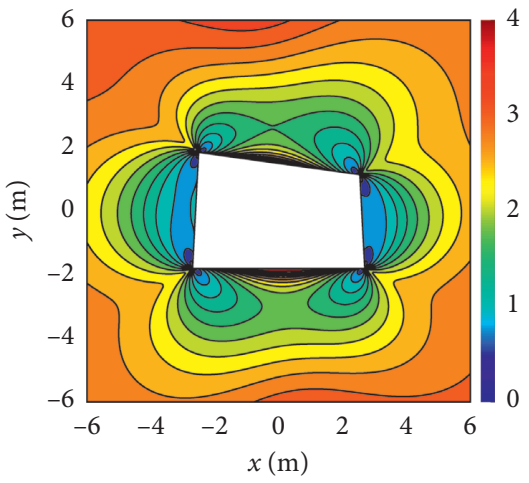

(g)

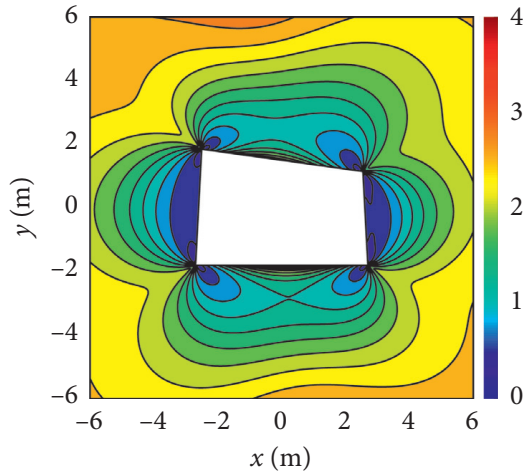

(b)

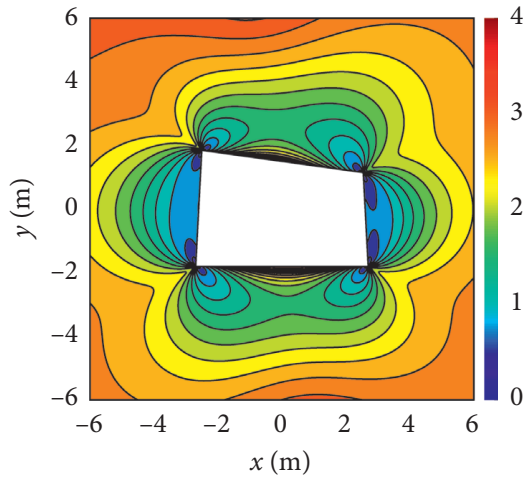

(e)

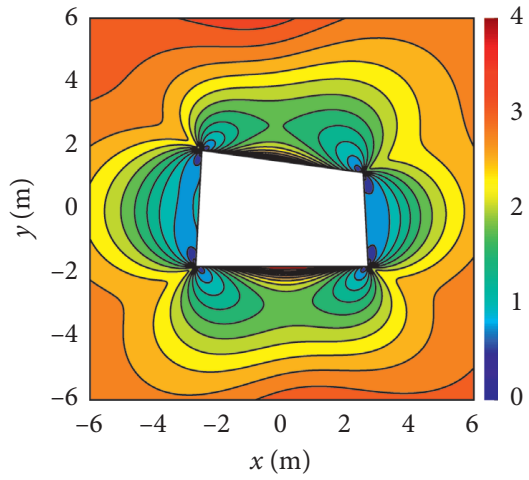

(h)

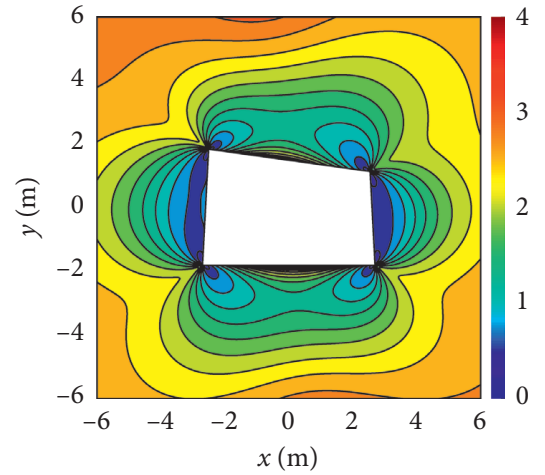

(c)

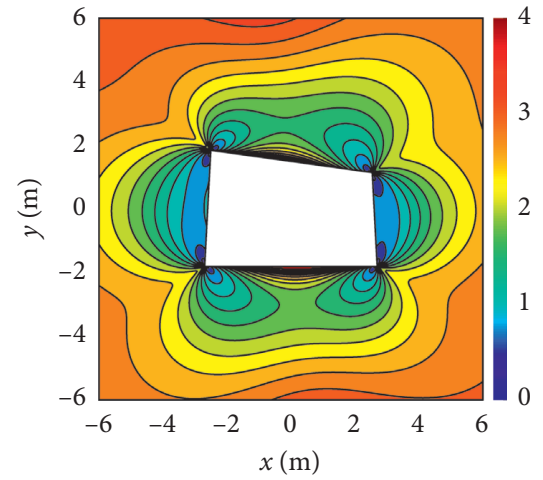

(f)

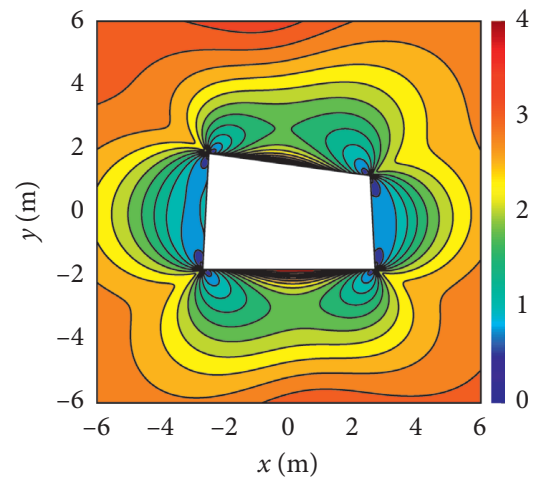

(i)

FIGURE 5: Contour map of SRSI at different distances from the working face. (a) $1=30 \mathrm{~m}$. (b) $\mathrm{l}=60 \mathrm{~m}$. (c) $\mathrm{l}=80 \mathrm{~m}$. (d) $\mathrm{l}=100 \mathrm{~m}$. (e) $\mathrm{l}=120 \mathrm{~m}$. (f) $l=160 \mathrm{~m}$. (g) $l=200 \mathrm{~m}$. (h) $\mathrm{l}=250 \mathrm{~m}$. (i) $\mathrm{l}=300 \mathrm{~m}$.

the boundary conditions, the working resistance of the bolt is superposed onto the stress distribution of the surrounding rock of the roadway, and the distribution of SRSI with support conditions is obtained. The contour map of SRSI with different anchoring methods is shown in Figures 10 and 11. The distribution of SRSI at $0.3 \mathrm{~m}$ from the roadway surface is shown in Figure 12. Equation (3) shows calculation of the AUAs of the roof and floor and the two sides under the conditions of the end anchoring bolt support and the fulllength anchoring bolt support when the distances from the working face are different, as shown in Figure 13.

Compared with Figures 5, 10, and 11, it can be seen that the SRSI of the shallow area is greater than that of the nosupport area when there is support and that of the full-length anchoring bolt support is greater than that of the end anchoring bolt support, indicating that both the end anchoring bolt support and the full-length anchoring bolt support can improve the stability of the surrounding rock. Moreover, the control effect of the full-length anchoring bolt support on the surrounding rock is stronger than that of the end anchoring bolt support. Compared with Figures 12(a) and 12(b), it can be clearly observed that, at the corner, the SRSI is higher with the full-length anchoring bolt support than that with the end anchoring bolt support, as shown by arrows $a, b, c, d, e$, and $f$ and $\mathbf{a}^{\prime}, \mathbf{b}^{\prime}, \mathbf{c}^{\prime}, \mathbf{d}^{\prime}, \mathbf{e}^{\prime}$, and $\mathbf{f}^{\prime}$ in Figure 12. The SRSI in the middle of the rock wall is approximately the same as that when adopting the full-length anchoring or end anchoring bolt support, as shown by arrows $g, h$, and $l$ and 


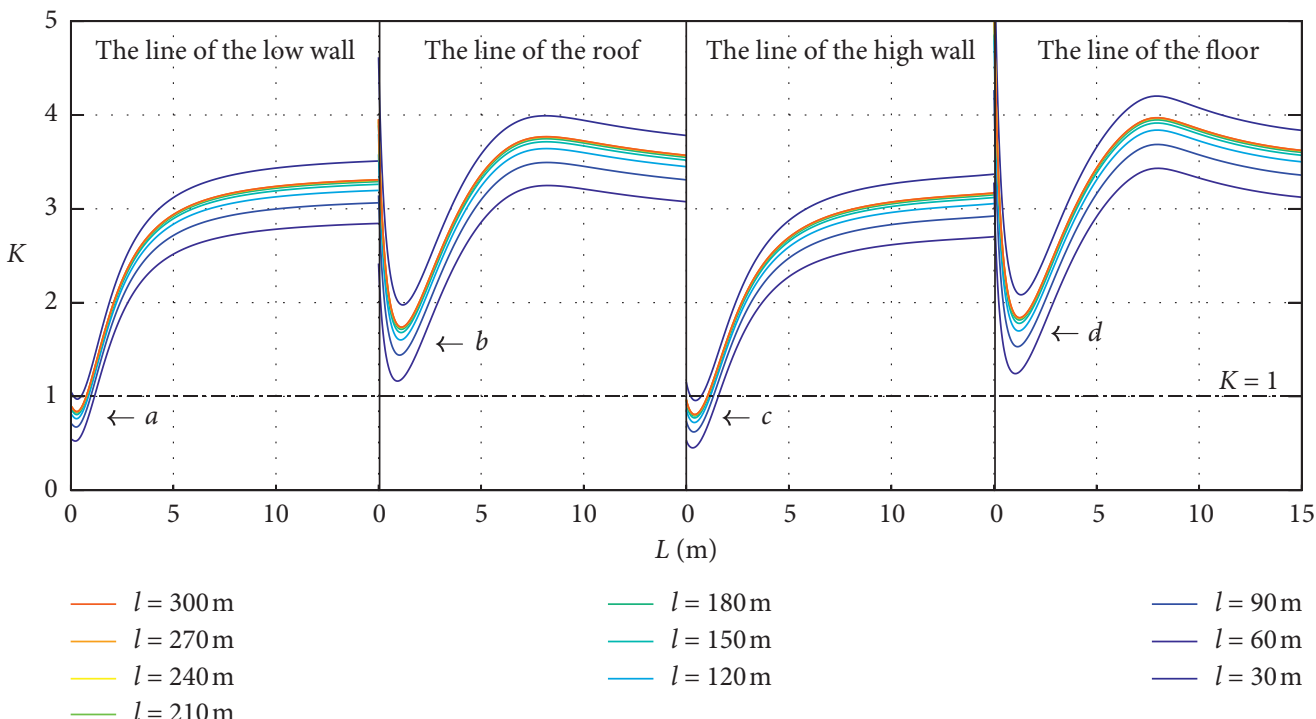

(a)

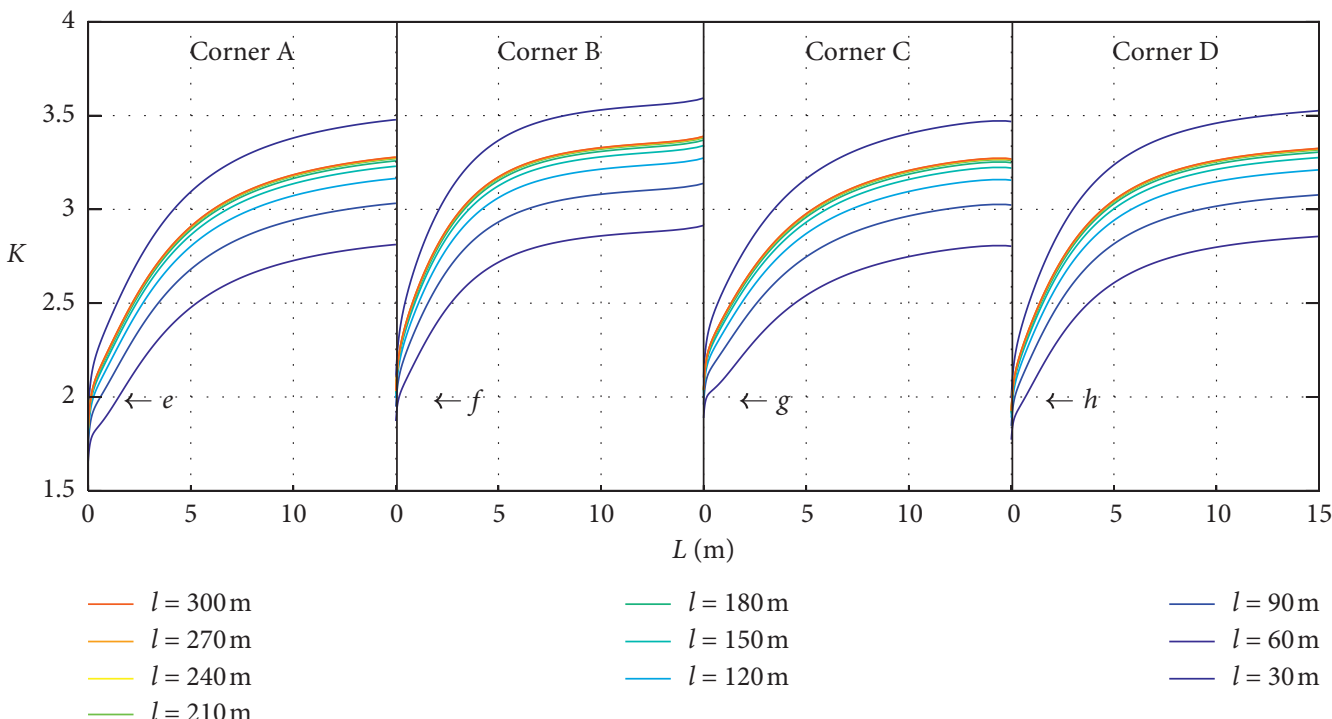

(b)

FIGURE 6: SRSI curve at the radial survey line of IRMR at different distances from working face. (a) The survey line of the rock wall. (b) The survey line of the corners.

$\mathbf{g}^{\prime}, \mathbf{h}^{\prime}$, and $\mathbf{l}^{\prime}$ in Figure 12. This shows that the full-length anchoring bolt support is better than the end anchoring bolt support in controlling the surrounding rock deformation at the corners of the roadway. Meanwhile, the full-length anchoring bolt support or the end anchoring bolt support has the same control effect on the middle of the rock wall. The main reason for this is that the working resistance of the bolt with full-length anchoring bolt support at the corners is higher than that of the bolt with end anchoring bolt support, while the working resistance of the bolt at the middle of the rock wall is similar to the roadway with end anchoring or full-length anchoring bolt support.

It can be seen from Figure 13 that, under the conditions of end anchoring bolt support, full-length anchoring bolt support, or no support, the AUAs of the roof and floor and the two sides tend to be the same as that with the mining. Before the peak of the abutment pressure and being less affected by the mining stress, the AUA curve under the condition of the full-length anchoring bolt support is located below the AUA curve under the condition of the end anchoring bolt support, as shown in part (a) in Figure 12. This shows that the AUA with the full-length anchoring bolt support is significantly smaller than that of the end anchoring bolt support, and the supporting effect of the fulllength anchoring bolt support is better than that of the end anchoring bolt support. At the peak of the abutment pressure and after the peak of the abutment pressure, the AUA curves with the full-length anchoring bolt support or the end anchoring bolt are basically coincident, as shown in part (b) in Figure 12. This shows that, at the peak of the 


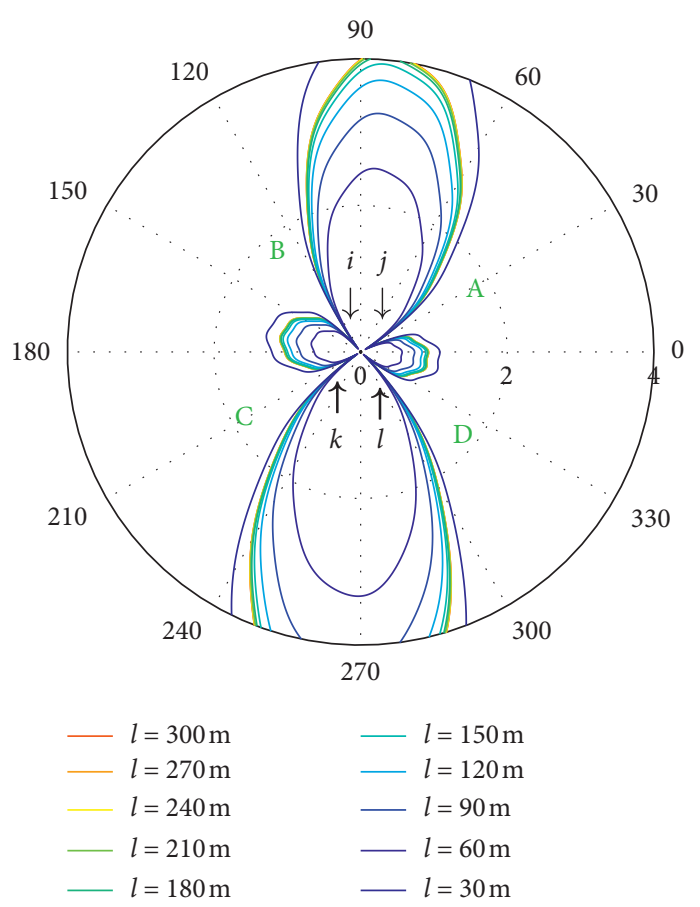

(a)

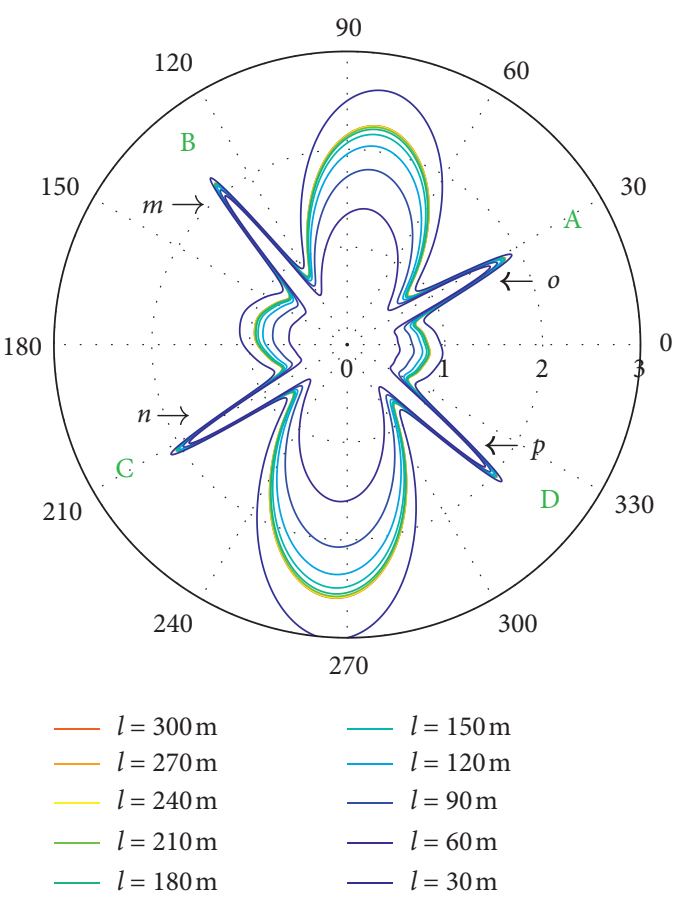

(b)

FIGURE 7: SRSI curve at the circumferential survey line of IRMR at different distances from the working face. (a) Surrounding rock surface. (b) Inner depth of surrounding rock $0.3 \mathrm{~m}$.

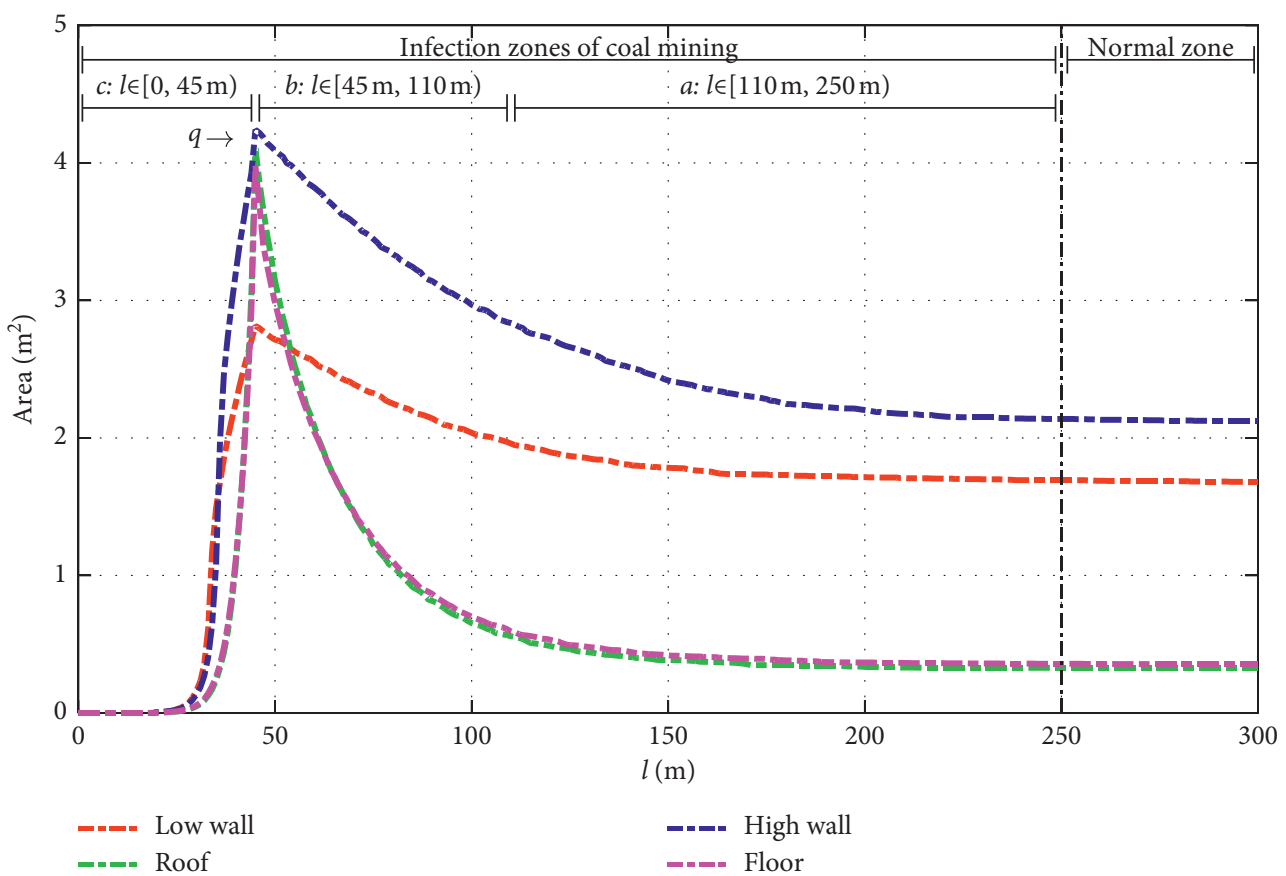

Figure 8: The curve of the AUA of the two sides and the roof and floor upon mining.

abutment pressure and after the peak of the abutment pressure, there is little difference between the AUAs under the conditions of the end anchoring bolt support and the full-length anchoring bolt support, and the supporting effect of the full-length anchoring bolt support is equivalent to that of the end anchoring bolt support.
3.4. Analysis of Control Effect of Field Surrounding Rock. In the 17102(3) working face, three groups of stations are arranged in the full-length anchoring bolt support zone and the end anchoring bolt support zone. The cross-point method is used to observe the surface deformation of the IRMR during mining. The surface deformation is shown in 


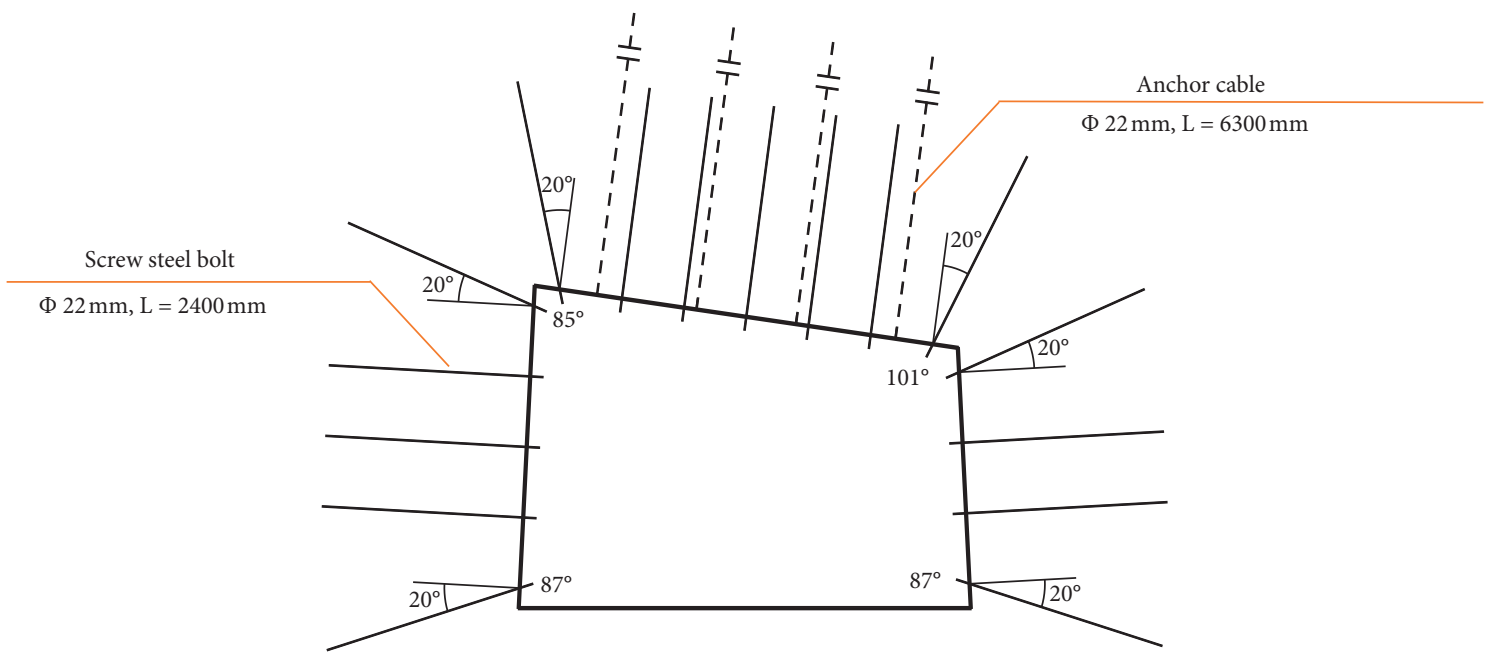

Figure 9: Schematic diagram of the roadway support.

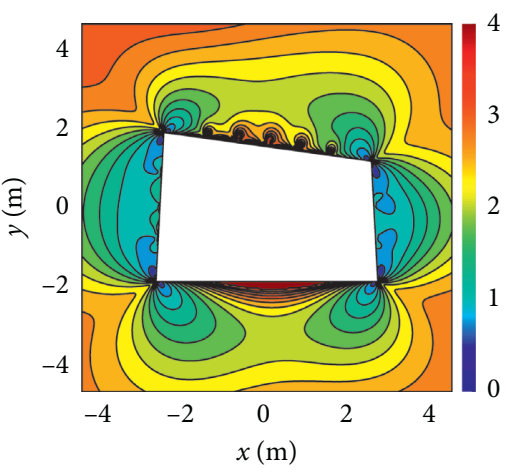

(a)

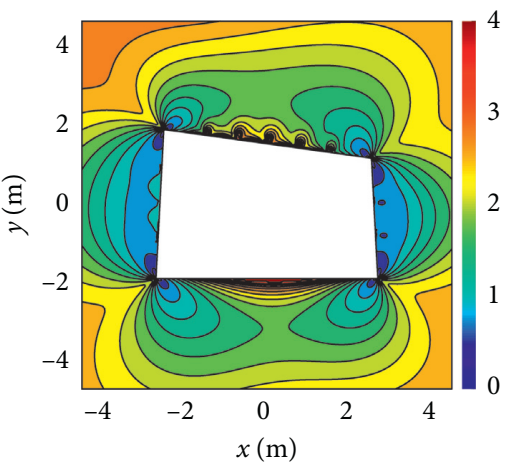

(d)

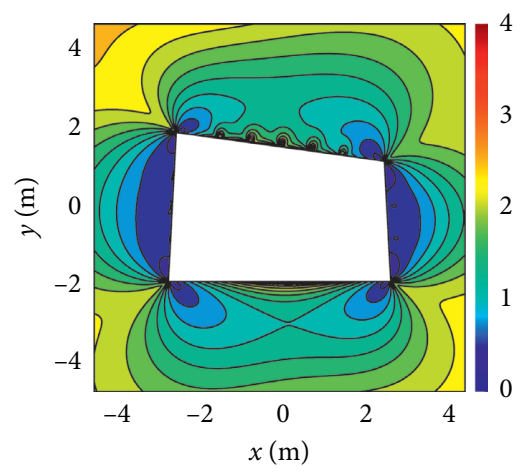

(b)

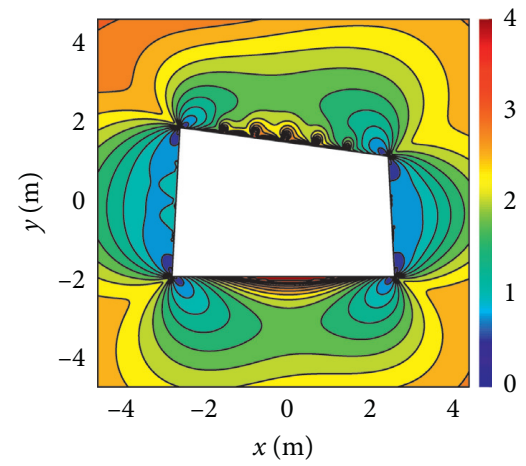

(e)

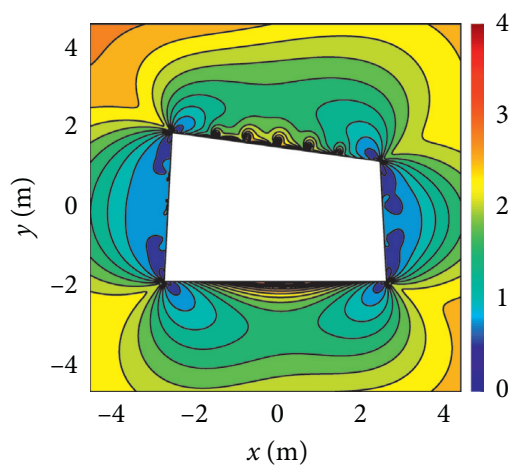

(c)

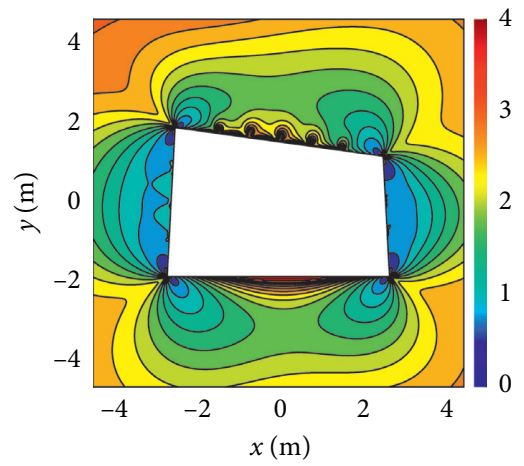

(f)

FIGURE 10: Contour map of SRSI of IRMR in the end anchoring zone at different distances from the working face. (a) $\mathrm{l}=30 \mathrm{~m}$. (b) $\mathrm{l}=60 \mathrm{~m}$. (c) $l=100 \mathrm{~m}$. (d) $\mathrm{l}=140 \mathrm{~m}$. (e) $\mathrm{l}=200 \mathrm{~m}$. (f) $\mathrm{l}=300 \mathrm{~m}$.

Figure 14. The surface deformation rate is shown in Figure 15. In the figure, stations 1,2 , and 3 are arranged in the full-length anchoring bolt support zone, and stations 4, 5, and 6 are arranged in the end anchoring bolt support zone.

According to the calculations in Figure 14, the average values of the roof to floor displacements and the two-side displacements with the full-length anchoring bolt support are $946.67 \mathrm{~mm}$ and $452.32 \mathrm{~mm}$, respectively, and the average values of the roof to floor displacements and the two-side displacements with the end anchoring bolt support are $1421.26 \mathrm{~mm}$ and $526.66 \mathrm{~mm}$. It can be seen from Figure 14 that the deformation curve in the full-length anchoring bolt support zone is below the deformation curve in the end anchoring bolt support zone. The deformation in the fulllength anchoring bolt support zone is less than that in the end anchoring bolt support zone, and the full-length anchoring bolt support effect is better than that of the end anchoring bolt support. According to Figures 13 and 14, 


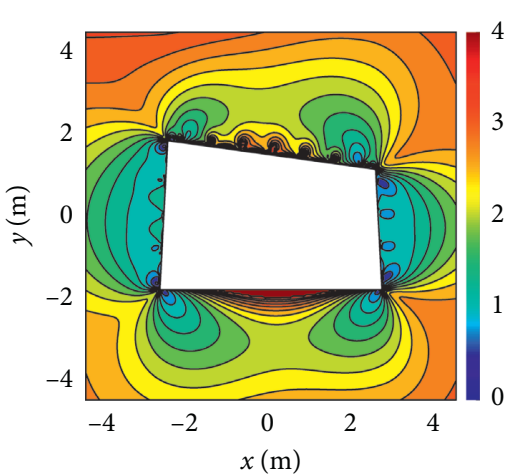

(a)

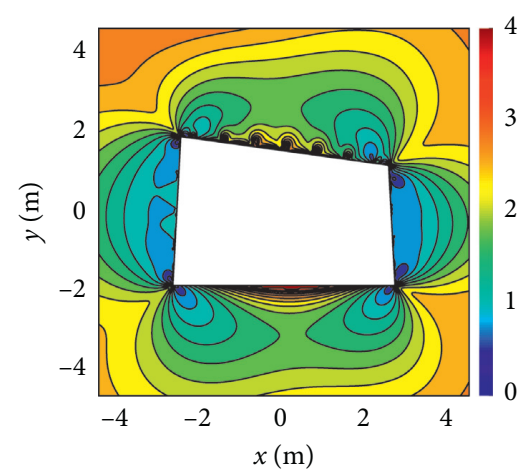

(d)

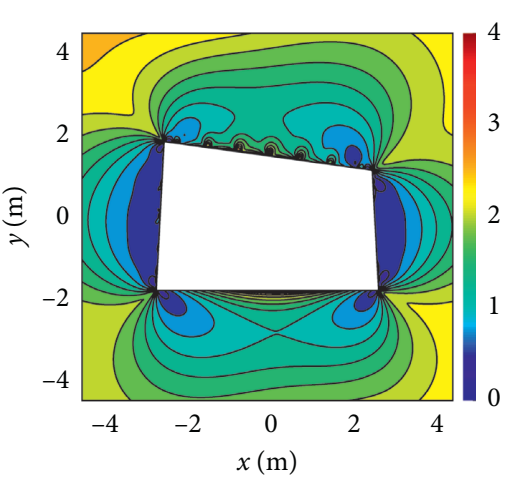

(b)

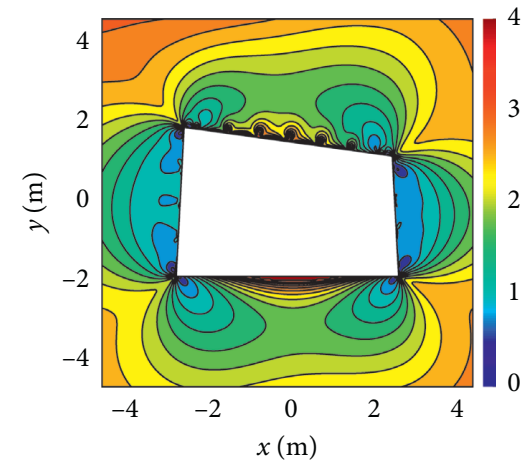

(e)

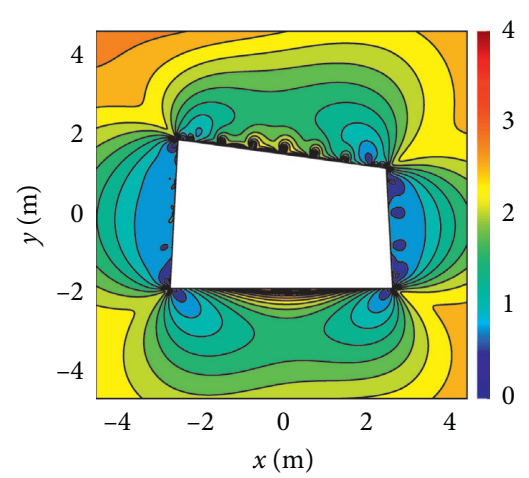

(c)

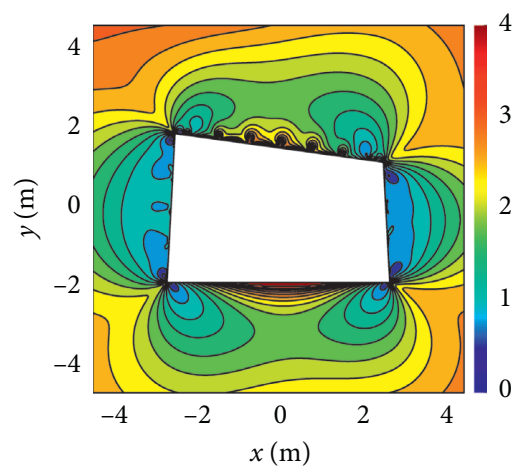

(f)

FIGURE 11: Contour map of SRSI of IRMR in the full-length anchoring zone at different distances from the working face. (a) $1=30 \mathrm{~m}$. (b) $l=60 \mathrm{~m}$. (c) $\mathrm{l}=100 \mathrm{~m}$. (d) $\mathrm{l}=140 \mathrm{~m}$. (e) $\mathrm{l}=200 \mathrm{~m}$. (f) $\mathrm{l}=300 \mathrm{~m}$.
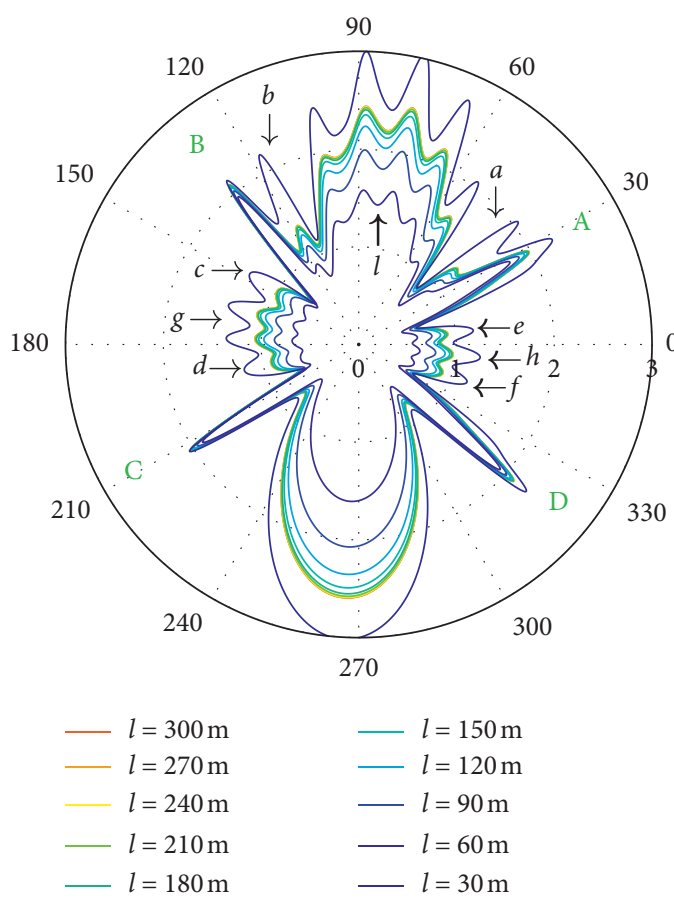

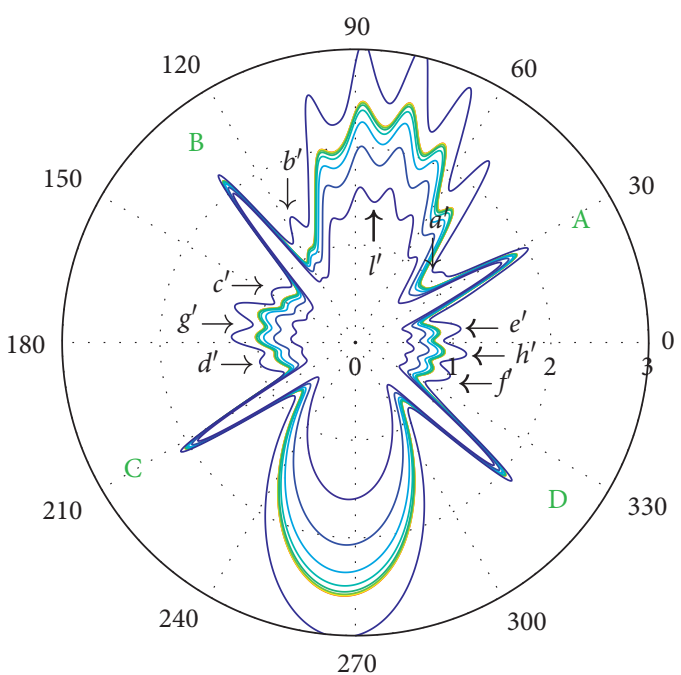

$$
\begin{aligned}
l & =150 \mathrm{~m} \\
-l & =120 \mathrm{~m} \\
-l & =90 \mathrm{~m} \\
-l & =60 \mathrm{~m} \\
-l & =30 \mathrm{~m}
\end{aligned}
$$

(a)

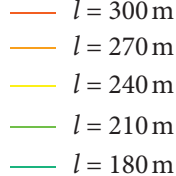

$l=180 \mathrm{~m}$

$$
\begin{aligned}
l & =150 \mathrm{~m} \\
-l & =120 \mathrm{~m} \\
-l & =90 \mathrm{~m} \\
-l & =60 \mathrm{~m} \\
-l & =30 \mathrm{~m}
\end{aligned}
$$

(b)

FIGURE 12: SRSI on the circumferential line of the end anchoring zone and the full-length anchoring zone. (a) Full-length anchoring. (b) End anchoring. 


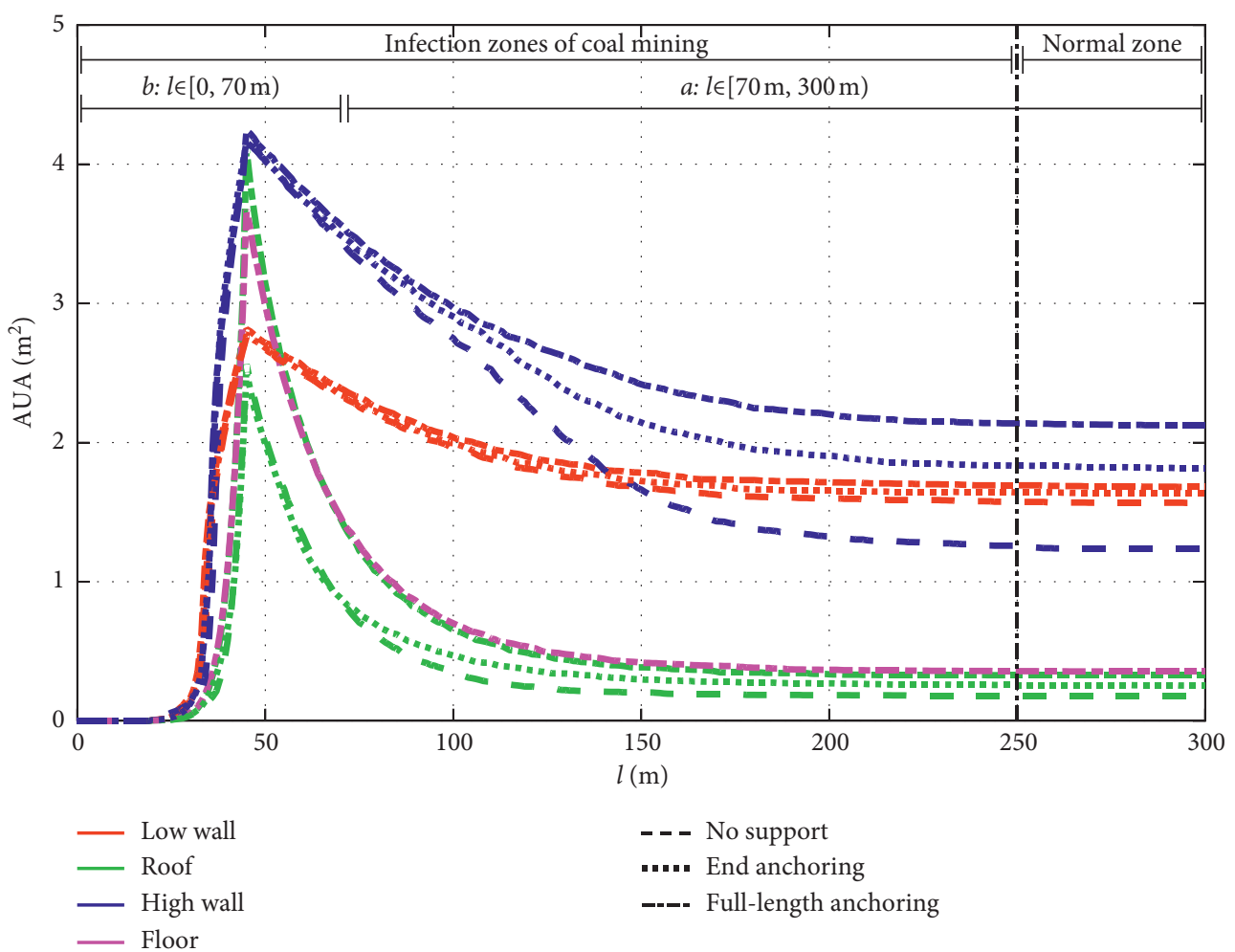

FIgUre 13: The curve of the AUA with no support, end anchoring bolt support, and full-length anchoring bolt support.

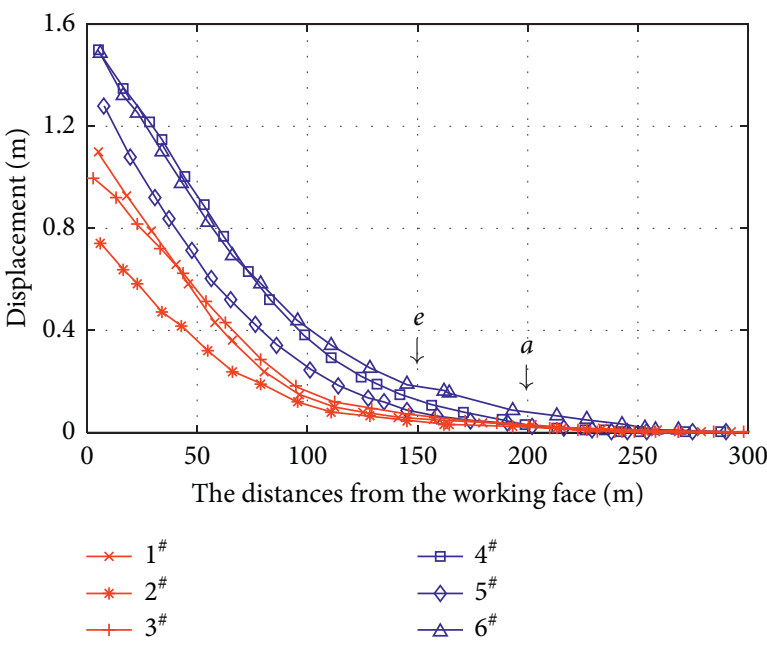

(a)

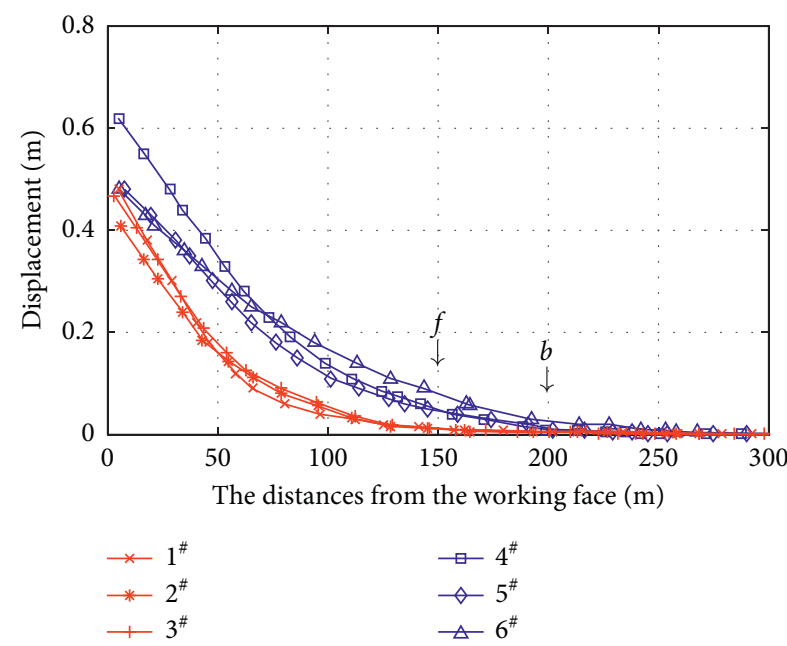

(b)

FIGURE 14: The surface deformation of the IRMR. (a) The displacement of the roof to floor. (b) The displacement of the tow side.

when the stations in the end anchoring bolt support zone are about $200 \mathrm{~m}$ away from the working face, the deformation begins to increase significantly, as shown by arrows $a, b, c$, and $d$ in Figures 13 and 14. However, the displacement in the full-length anchoring bolt support zone increases significantly when stations are about $150 \mathrm{~m}$ away from the working face, as shown by arrows $e, f, g$, and $h$ in Figures 13 and 14 . At the peak of the abutment pressure, the displacement rate of the full-length anchoring bolt support zone is obviously lower than that of the full-length anchoring bolt support zone, as shown by sections $i$ and $j$ in Figure 15. The main reason for this is that, before the peak of the abutment pressure, compared with that of the end anchoring bolt support, the full-length anchoring bolt support reduces the AUA to a greater extent, as shown in part (a) in Figures 13; thus, the surrounding rock is more stable when adopting 


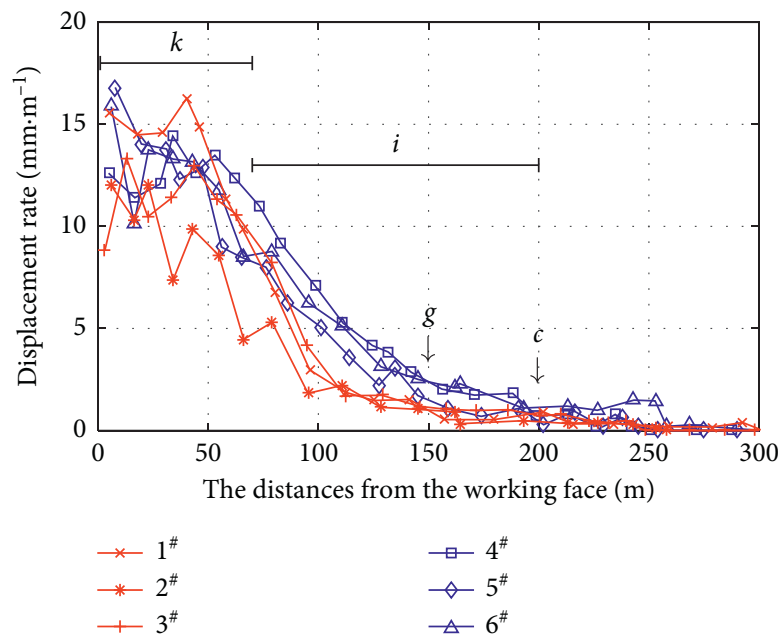

(a)

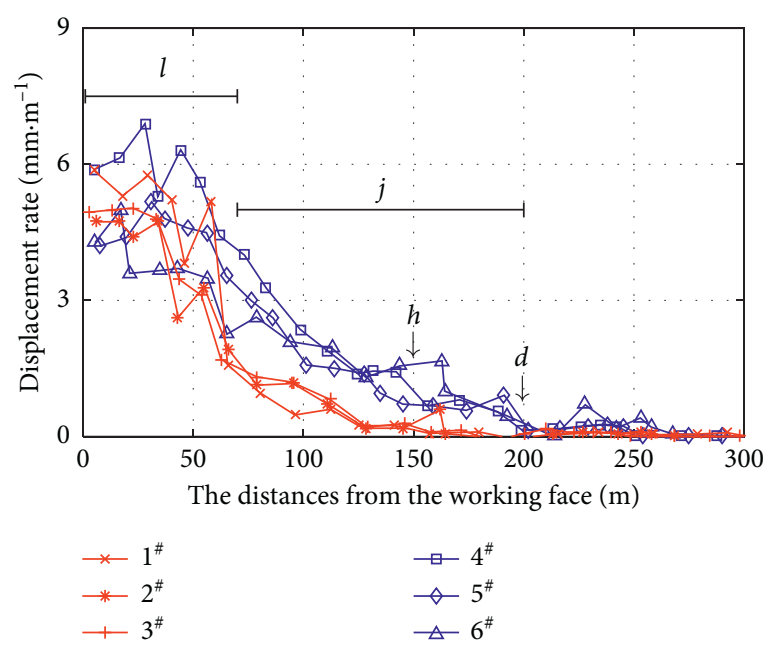

(b)

FIgURE 15: The surface deformation rate of the IRMR. (a) The displacement rate of the roof to floor. (b) The displacement rate of the tow side.

full-length anchoring bolt support. Near and after the peak of the abutment pressure, the displacement rates of the surrounding rock in the full-length anchoring bolt support zone and the end anchoring bolt support zone are slightly different as shown in section $k$ and $l$ in Figure 15. The main reason for this is that, near and after the peak of the abutment pressure, there is little difference in the AUAs of the surrounding rock under the conditions of the full-length anchoring bolt support and the end anchoring bolt support. The full-length anchoring bolt support of this part is equivalent to the end anchoring bolt support. In conclusion, it can be concluded that the full-length anchoring bolt support effect is significantly better than the end anchoring bolt support, and the theoretical analysis results are verified.

\section{Conclusions}

In order to study the stability characteristics of the surrounding rock and the control effect of bolt support with different anchoring methods under the influence of mining stress, the SRSI is defined and solved based on the rock strength criterion and the stress distribution. The MohrCoulomb strength criterion and a complex function method are used to solve the analytical solution of the SRSI. Combined with the actual conditions, through the analysis of the changes of the SRSIs and the AUAs under the conditions of no support, the end anchoring bolt support, and the full-length anchoring bolt support, the evolution law of the stability characteristics with the mining is obtained. Combined with the observation data of the deformation, the supporting effects of the full-length and the end anchoring bolt support are analyzed. The conclusion is as follows:

(1) Based on the rock strength criterion and stress distribution of the surrounding rock, the SRSI is defined, which is a more reasonable and effective method with which to analyze the stability characteristics of the surrounding rock. Based on the MohrCoulomb strength criterion and a complex function method, the analytical solution of the SRSI of IRMR is obtained. The SRSI can comprehensively reflect the influence of the shape of the roadway section, the stress conditions, and the strength parameters on the stability characteristics.

(2) Under the condition of no support and without the influence of mining stress, the AUAs of low wall and high wall are $1.68 \mathrm{~m}^{2}$ and $2.12 \mathrm{~m}^{2}$, respectively. Thus, the AUA of the high wall is larger than that of the low wall, and the low wall is more stable. The AUAs of the roof and floor are $0.33 \mathrm{~m}^{2}$ and $0.35 \mathrm{~m}^{2}$. Compared with that of the two sides, the roof and floor are more stable. Before the peak of the abutment pressure, the SRSI decreases, the AUA increases, and the stability decreases as a whole. After the peak of the abutment pressure, the AUA decreases to 0 and the stability of the surrounding rock increases.

(3) The theoretical analysis shows that, compared with the end anchoring bolt support, the full-length anchoring bolt support method reduces the AUA to a greater extent. The surrounding rock in the end anchoring zone and the full-length anchoring zone began to deform significantly at $200 \mathrm{~m}$ and $150 \mathrm{~m}$ from the working face, respectively. The control effect of the full-length anchoring bolt support is better than that of the end anchoring bolt support and verifies the rationality of SRSI to describe the instability characteristics.

\section{Data Availability}

The data used to support the findings of this study are available from the corresponding author upon request.

\section{Conflicts of Interest}

The authors declare no conflicts of interest. 


\section{Acknowledgments}

This work was supported by the National Natural Science Foundation of China (nos. 51774009 and 51874006); Key Research and Development Projects in Anhui Province (no. 202004a07020045); and Colleges and Universities Natural Science Foundation of Anhui (no. KJ2019A0134).

\section{References}

[1] Q. Wang, Z. X. Xin, B. Jiang et al., "Comparative experimental study on mechanical mechanism of combined arches in large section tunnels," Tunnelling and Underground Space Technology, vol. 99, Article ID 103386, 2020.

[2] L. Obert and W. I. Duvall, Rock Mechanics and the Design of Structures in Rock, John Wiley and Sons, New York, NY, USA, 1st edition, 1967.

[3] C. Yuan, W. Wang, and L. Fan, "Study on distribution law and influencing factors of surrounding rock plastic zone in mining roadway," Journal of Vibroengineering, vol. 21, no. 4, pp. 1127-1138, 2019.

[4] H. Y. Liu, Z. G. Wang, J. Li, and L. Bai, "Coal seam roadway bolt support design method based on the supporting theory of broken rock zone," Advanced Materials Research, vol. 734-737, pp. 535-539, 2013.

[5] G. Li, N. Zhang, C. Wang, N. Zhang, and B. Li, "Optimizing the section shape of roadways in high stress ground by numerical simulation," Journal of China University of Mining and Technology, vol. 39, no. 5, pp. 652-658, 2010.

[6] Q. Meng, L. Han, W. Qiao, D. Lin, and L. Wei, "Numerical simulation of cross-section shape optimization design of deep soft rock roadway under high stress," Journal of Mining and Safety Engineering, vol. 29, no. 5, pp. 651-656, 2012.

[7] L. Hu, H. Su, B. Ma, and C. Li, "The influence research of roadway cross-section structure on the surrounding rock deformation," Safety in Coal Mines, vol. 43, no. 3, pp. 25-27, 2012.

[8] L. A. Panek, Use of Vertical Roof Bolts to Reinforce an Arbitrary Sequence of Beds, Mining Research, Park Hills, MO, USA, 1962.

[9] S. S. Peng and D. H. Y. Tang, "Roof bolting in underground mining: a state-of-the-art review," International Journal of Mining Engineering, vol. 2, no. 1, pp. 1-42, 1984.

[10] Q. Wu, X. Li, L. Weng, Q. Li et al., "Experimental investigation of the dynamic response of prestressed rockbolt by using an SHPB-based rockbolt test system," Tunneling and Underground Space Technology, vol. 93, Article ID 103088, 2019.

[11] J. Chen, F. He, and S. Zhang, "A study of the load transfer behavior of fully grouted rock bolts with analytical modelling," International Journal of Mining Science and Technology, vol. 30, no. 1, pp. 105-109, 2020.

[12] M. H. Aghchai, P. Maarefvand, and H. S. Rad, "Analytically determining bond shear strength of fully grouted rock bolt based on pullout test results," Periodica Polytechnica Civil Engineering, vol. 64, pp. 212-222, 2020.

[13] L. Cui, Y.-K. Dong, Q. Sheng, and Q. Shen, "New numerical procedures for fully-grouted bolt in the rock mass with slip and non-slip cases at the rock-bolt interface," Construction and Building Materials, vol. 204, pp. 849-863, 2019.

[14] J. Zou and P. Zhang, "Analytical model of fully grouted bolts in pull-out tests and in situ rock masses," International Journal of Rock Mechanics and Mining Sciences, vol. 113, pp. 278-294, 2019.
[15] C. Wu, X. Chen, Y. Hong, R. Xu, and D. Yu, "Experimental investigation of the tensile behavior of rock with fully grouted bolts by the direct tensile test," Rock Mechanics and Rock Engineering, vol. 51, no. 1, pp. 351-357, 2018.

[16] G. Liu, M. Xiao, J. Chen, and H. Zhou, "Study on mechanical characteristics of fully grouted rock bolts for underground caverns under seismic loads," Mathematical Problems in Engineering, vol. 2017, pp. 1-12, Article ID 1657369, 2017.

[17] Y. Chen, G. Wen, and J. Hu, "Analysis of deformation characteristics of fully grouted rock bolts under pull-andshear loading," Rock Mechanics and Rock Engineering, vol. 53, no. 7, pp. 2981-2993, 2020.

[18] N. I. Muskhelishvili and P. Noordhoff, Some Basic Problems of the Mathematical Theory of Elasticity, Cambridge University Press, Cambridge, UK, 4th edition, 1953.

[19] Q. Feng, B.-S. Jiang, Q. Zhang, and L.-P. Wang, "Analytical elasto-plastic solution for stress and deformation of surrounding rock in cold region tunnels," Cold Regions Science and Technology, vol. 108, pp. 59-68, 2014.

[20] W. Shen, X. Wang, J. Bai, W. Li, and Y. Yu, "Rock stress around noncircular tunnel: a new simple mathematical method," Advances in Applied Mathematics and Mechanics, vol. 9, no. 6, pp. 1330-1346, 2017.

[21] H. T. Manh, J. Sulem, and D. Subrin, "A closed-form solution for tunnels with arbitrary cross section excavated in elastic anisotropic ground," Rock Mechanics and Rock Engineering, vol. 48, no. 1, pp. 277-288, 2015.

[22] A. R. Kargar, R. Rahmannejad, and M. A. Hajabasi, "A semianalytical elastic solution for stress field of lined non-circular tunnels at great depth using complex variable method," International Journal of Solids and Structures, vol. 51, no. 6, pp. 1475-1482, 2014.

[23] Z. Guo, X. Liu, and Z. Zhu, "Elastic solution for a deep twin tunnel's stress based on complex variable theory and the superposition principle," Journal of Engineering Research, vol. 5, no. 2, pp. 68-86, 2017.

[24] A. Nazem, M. Hossaini, H. Rahami, and R. Bolghonabadi, "Optimization of conformal mapping functions used in developing closed-form solutions for underground structures with conventional cross sections," International Journal of Mining and Geo-Engineering, vol. 49, no. 1, pp. 93-102, 2015.

[25] N. V. Challis and D. M. Burley, "A numerical method for conformal mapping," IMA Journal of Numerical Analysis, vol. 2, no. 2, pp. 169-181, 1982.

[26] T. K. DeLillo, A. R. Elcrat, and J. A. Pfaltzgraff, "Numerical conformal mapping methods based on faber series," Journal of Computational and Applied Mathematics, vol. 83, no. 2, pp. 205-236, 1997.

[27] A. Gopal and L. N. Trefethen, "Representation of conformal maps by rational functions," Numerische Mathematik, vol. 142, no. 2, pp. 359-382, 2019.

[28] M. M. S. Nasser and F. A. A. Al-Shihri, "A fast boundary integral equation method for conformal mapping of multiply connected regions," SIAM Journal on Scientific Computing, vol. 35, no. 3, pp. A1736-A1760, 2013.

[29] K. Amano, D. Okano, H. Ogata, and M. Sugihara, "Numerical conformal mappings onto the linear slit domain," Japan Journal of Industrial and Applied Mathematics, vol. 29, no. 2, pp. 165-186, 2012.

[30] B. Yu and L. Zhang, "Study on the abutment pressure distribution in top coal caving," Arabian Journal of Geosciences, vol. 13, no. 4, Article ID 162, 2020.

[31] Z. Wang, L. Yin, J. Chen, and K. Ma, "Research on distribution law of advanced abutment pressure in deep soft rock 
working face," Geotechnical and Geological Engineering, vol. 37, no. 5, pp. 4089-4097, 2019.

[32] Q. Zhang, C.-H. Peng, R.-C. Liu, B.-S. Jiang, and M.-M. Lu, "Analytical solutions for the mechanical behaviors of a hard roof subjected to any form of front abutment pressures," Tunnelling and Underground Space Technology, vol. 85, pp. 128-139, 2019.

[33] H. Han, J. Xu, X. Wang, J. Xie, and Y. Xing, "Method to calculate working surface abutment pressure based on key strata theory," Advances in Civil Engineering, vol. 2019, pp. 1-20, Article ID 7678327, 2019.

[34] L. Cheng and Y. Zhang, "A new closed-form solution of the side abutment pressure distribution of roadway," Advances in Civil Engineering, vol. 2018, pp. 1-10, Article ID 1409493, 2018. 